\title{
Regional Patterns of Tropical Indo-Pacific Climate Change: Evidence of the Walker Circulation Weakening*
}

\author{
Hiroki Tokinaga, Shang-Ping Xie, And Axel Timmermann \\ International Pacific Research Center, SOEST, University of Hawaii at Manoa, Honolulu, Hawaii \\ SHAYNE MCGREGOR \\ Climate Change Research Centre, University of New South Wales, Sydney, New South Wales, Australia \\ TOMOMICHI OGATA \\ International Pacific Research Center, SOEST, University of Hawaii at Manoa, Honolulu, Hawaii \\ HISAYUKI KUBOTA \\ Japan Agency for Marine-Earth Science and Technology, Yokosuka, Japan \\ YUKO M. OKUMURA \\ National Center for Atmospheric Research, Boulder, Colorado
}

(Manuscript received 16 May 2011, in final form 16 August 2011)

\begin{abstract}
Regional patterns of tropical Indo-Pacific climate change are investigated over the last six decades based on a synthesis of in situ observations and ocean model simulations, with a focus on physical consistency among sea surface temperature (SST), cloud, sea level pressure (SLP), surface wind, and subsurface ocean temperature. A newly developed bias-corrected surface wind dataset displays westerly trends over the western tropical Pacific and easterly trends over the tropical Indian Ocean, indicative of a slowdown of the Walker circulation. This pattern of wind change is consistent with that of observed SLP change showing positive trends over the Maritime Continent and negative trends over the central equatorial Pacific. Suppressed moisture convergence over the Maritime Continent is largely due to surface wind changes, contributing to observed decreases in marine cloudiness and land precipitation there.

Furthermore, observed ocean mixed layer temperatures indicate a reduction in zonal contrast in the tropical Indo-Pacific characterized by larger warming in the tropical eastern Pacific and western Indian Ocean than in the tropical western Pacific and eastern Indian Ocean. Similar changes are successfully simulated by an ocean general circulation model forced with the bias-corrected wind stress. Whereas results from major SST reconstructions show no significant change in zonal gradient in the tropical Indo-Pacific, both bucket-sampled SSTs and nighttime marine air temperatures (NMAT) show a weakening of the zonal gradient consistent with the subsurface temperature changes. All these findings from independent observations provide robust evidence for ocean-atmosphere coupling associated with the reduction in the Walker circulation over the last six decades.
\end{abstract}

* International Pacific Research Center Publication Number 814 and School of Ocean and Earth Science and Technology Publication Number 8486.

Corresponding author address: Hiroki Tokinaga, International Pacific Research Center, University of Hawaii at Manoa, EastWest Road, Post 401, Honolulu, HI 96822.

E-mail: tokinaga@hawaii.edu

\section{Introduction}

Tropical patterns of long-term ocean warming have the potential to exert a strong influence on global climate (Alexander et al. 2002; Collins et al. 2010; DiNezio et al. 2009; Xie et al. 2010). Coupled general circulation models (GCMs) predict suppressed equatorial upwelling in the tropical Pacific under the increased greenhouse gas (GHG) forcing, accompanied by a slowdown 
of the Walker circulation (Vecchi and Soden 2007). An equatorial maximum of sea surface temperature (SST) warming anchors a band of strong precipitation increase with potential effects on tropical cyclones (Xie et al. 2010). These changes are some of the robust responses to global warming among coupled GCMs participating in phase 3 of the Coupled Model Intercomparison Project (CMIP3) (Held and Soden 2006; Vecchi and Soden 2007).

It remains challenging to identify physically consistent patterns of climate change from observations because of the limited samplings in space and time, changes in observational practice, and biases between measurement methods (Deser et al. 2010; Kent and Taylor 2006; Vecchi et al. 2008). Marine surface winds observed by ships, an important parameter relating SST warming and regional sea level change in the tropics, suffer from strong biases as anemometer height increases during recent decades (Bunker 1980; Cardone et al. 1990; Ramage 1987; Thomas et al. 2008; Whysall et al. 1987). The resultant wind biases after 1950s cause a spurious intensification of the prevailing winds, which is inconsistent with changes in sea level pressure (SLP) gradient over the global ocean (Ward and Hoskins 1996). Tokinaga and Xie (2011a) corrected the wind bias with a stability-dependent height correction and by using windwave heights logged concurrently by voluntary observing ships (VOS). This bias-corrected wind dataset captures a significant relaxation of tropical Atlantic trade winds over the last six decades, a wind change pattern consistent with the weakening of the equatorial Atlantic cold tongue through positive Bjerknes-type feedback (Tokinaga and Xie 2011b).

Historical SST datasets have large uncertainties in long-term trend patterns. For example, observed SST changes in the tropical Pacific are still controversial, depending on the dataset and study period (Bunge and Clarke 2009; Cane et al. 1997; Deser et al. 2010; Hansen et al. 2005, 2006; Karnauskas et al. 2009). There are two major historical SST reconstructions available starting from the late nineteenth century: Hadley Centre sea ice and SST (HadISST; Rayner et al. 2003) and the National Oceanic and Atmospheric Administration (NOAA) Extended Reconstructed SST (ERSST; Smith and Reynolds 2004; Smith et al. 2008). Ship observations are used in both reconstructions, but satellite-based SSTs are blended only by HadISST. Vecchi et al. (2008) indicate that the equatorial zonal SST gradient in the Pacific has intensified in HadISST but weakened in ERSST from the nineteenth to twentieth centuries. This discrepancy is pronounced around the 1930s and 1980s, which roughly correspond to the periods of the appearance of engineroom intake SSTs and the beginning of satellite infrared
SST retrievals, respectively. Deser et al. (2010) suggest the poor data coverage in the equatorial Pacific makes it difficult to accurately estimate the long-term trend in the zonal SST gradient during the twentieth century.

SST and sea level changes in the tropical Indian Ocean have also generated a controversy among several studies. Coral oxygen-isotope records suggest that the frequency and strength of the Indian Ocean dipole (IOD; Saji et al. 1999) events have increased during the twentieth century because of the enhanced seasonal upwelling in the eastern Indian Ocean (Abram et al. 2008), supported by longterm simulations of the CMIP3 models (Du and Xie 2008; Zheng et al. 2010). In contrast, ocean GCM hindcasts forced by atmospheric reanalyses indicate an opposite change over the past half-century (Han et al. 2010; Trenary and Han 2008). Regional patterns of simulated sea level rise are dependent on the observational surface wind products with large uncertainty for long-term trends (Timmermann et al. 2010), but tide gauge observations are too limited in space and time for a conclusive test.

One of the keys to identify regional patterns of tropical Indo-Pacific climate change is to pin down the Walker circulation change. There are two possible mechanisms for Walker circulation change, in response to tropical SST patterns and to uniform warming. The former is associated with the atmospheric response to a weakening or strengthening of the equatorial cold tongue whereas the latter is unique to global warming and weakens the Walker circulation due to a more rapid increase in atmospheric static stability than the radiative cooling of the atmosphere (Knutson and Manabe 1995). Supporting the latter mechanism, idealized atmospheric GCM experiments indicate that the Walker circulation slows down without any change in zonal SST gradient owing to the vertical temperature advection by climatological upward and downward motion on a background of increased static stability under global warming (Gastineau et al. 2009; Ma et al. 2012). It is unclear, however, which mechanism is responsible for the observed change and whether the Walker circulation has strengthened or weakened over the last century. Whereas atmospheric reanalyses and GCMs forced with observed SSTs suggest an intensification of the Walker circulation (Chen et al. 2008; Meng et al. 2012; Sohn and Park 2010; Yu and Zwiers 2010), historical SLP and cloudiness reconstructions show a slowdown of the Walker circulation accompanied by an eastward shift of atmospheric deep convection from the Maritime Continent to the central equatorial Pacific (Deser et al. 2010; Power and Kociuba 2011; Power and Smith 2007; Vecchi et al. 2006). Ambiguous SST trends in the equatorial Pacific cold tongue hamper our way forward to the further understanding of tropical Indo-Pacific climate change. 
Under such controversies, it is necessary to examine physical consistencies among independent oceanatmosphere observations with careful consideration of error/bias characteristics of each dataset. The present study revisits regional patterns of tropical Indo-Pacific climate change by using a suite of independent historical datasets over the last six decades with careful quality controls and bias corrections. Besides a synthesis of SST, SLP, cloudiness, and rainfall datasets, we focus on changes in surface wind and subsurface ocean temperature, two variables closely related by robust ocean dynamics. We illustrate a robust ocean response to observed surface wind changes by ocean model hindcasts. Despite the fact that limited instrumental records still make it difficult to attribute observed changes to external forcing or natural variability, it is important to describe these changes for validation of climate models that are used for future climate projection. This methodology for pattern detection proves to be successful for the tropical Atlantic climate change (Tokinaga and Xie 2011b). A major finding of the present study is that the zonal contrast of equatorial subsurface temperature in the tropical IndoPacific has significantly weakened in response to surface wind changes associated with a weakened Walker circulation. Regarding the cause of atmospheric circulation change, we also examine SST warming patterns and uncertainties by comparison of the SST and nighttime marine air temperature reconstructions.

The rest of this paper is organized as follows. Section 2 introduces data and model used in the present study. Sections 3 and 4 investigate regional patterns of observed climate change over the tropical Pacific, the Maritime Continent, and the tropical Indian Ocean, incorporating ocean model simulations. Section 5 discusses possible biases of reanalysis products and SST reconstructions for studies of tropical climate change. Section 6 is a summary.

\section{Data and models}

\section{a. International Comprehensive Ocean-Atmosphere Dataset}

SST, SLP, and total marine cloudiness observations from the International Comprehensive Ocean-Atmosphere Dataset (ICOADS) release 2.5 (Woodruff et al. 2010) are used to construct a monthly mean dataset on a $4^{\circ}$ longitude-latitude grid for 1950-2009. All data have been trimmed using the ICOADS quality-control flag that identifies potential outliers based on the climatological 3.5 standard deviation limits. This is basically the same quality control as used for the standard product of the ICOADS Monthly Summary Groups available at the Research Data Archive (RDA) at the National Center for Atmospheric Research (NCAR). Missing data are

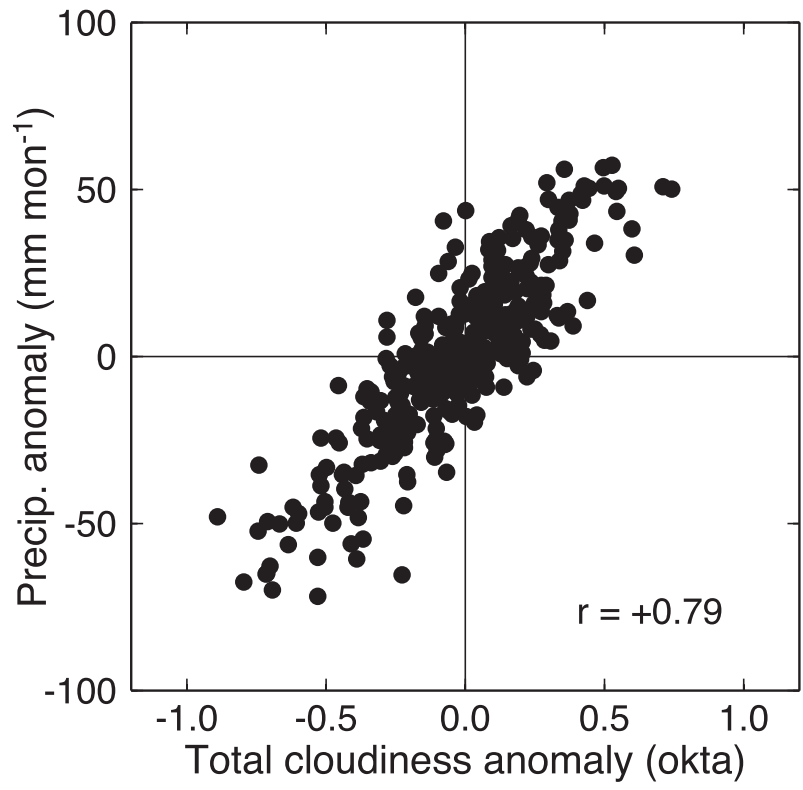

FIG. 1. Scatterplot of monthly mean cloudiness (okta) and precipitation $\left(\mathrm{mm}\right.$ month $^{-1}$ ) anomalies averaged over the Maritime Continent $\left(80^{\circ}-150^{\circ} \mathrm{E}, 20^{\circ} \mathrm{S}-20^{\circ} \mathrm{N}\right)$. Cloudiness (precipitation) data are obtained from ICOADS (GPCP).

filled with linear interpolation across "no data" grids not exceeding 5 points in longitude and 1 point in latitude. This interpolation is applied twice for the ICOADS observations to detect basin-scale characteristics.

Ship-observed marine cloudiness is known to have systematic biases (Norris 1999). To eliminate the biases, we remove the tropical $\left(30^{\circ} \mathrm{N}-30^{\circ} \mathrm{S}\right)$ mean cloudiness trend from each oceanic grid box following the procedure of Deser and Phillips (2006). While there is no historical precipitation record over the ocean before the satellite era, the ICOADS cloudiness, with the tropicalmean trend removed, can be used as a proxy of marine precipitation over atmospheric convective regions. Figure 1 compares the ICOADS cloudiness and the Global Precipitation Climatology Project (GPCP) marine precipitation anomalies averaged over the Maritime Continent for 1979-2008. The two parameters are highly correlated with correlation and regression coefficients of +0.79 and $+77.8 \mathrm{~mm}$ month ${ }^{-1} \mathrm{okta}^{-1}$, respectively, both of which exceed the $99 \%$ confidence level. Similar relationships between the two parameters can be found over other convective regions (not shown), indicating that convective clouds with precipitation largely contribute to the total cloudiness over such regions.

\section{b. Wave-and anemometer-based sea surface wind}

We use marine surface wind and wind stress observations from the Wave- and Anemometer-based Sea Surface Wind (WASWind) dataset available for 1950-2009 


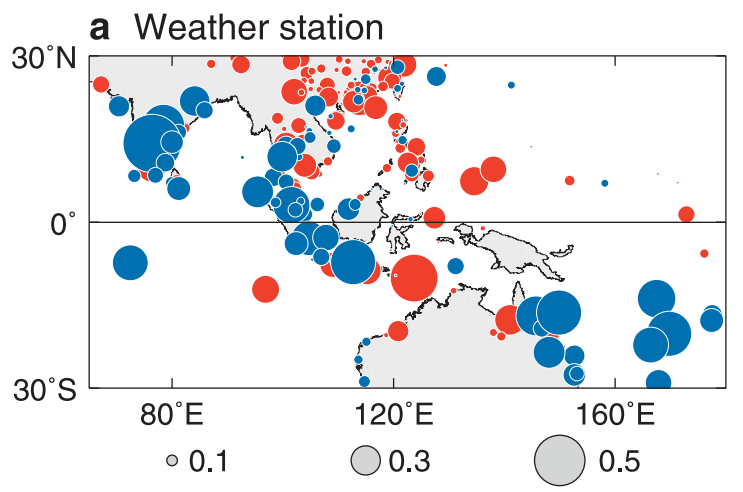

\section{b WASWind}

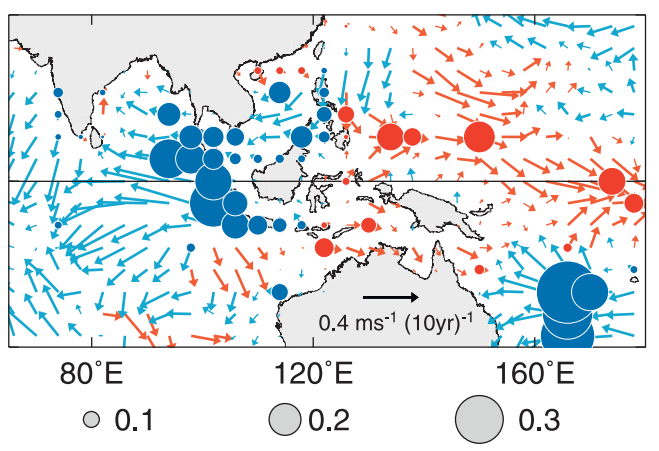

FIG. 2. June-October zonal wind changes for 1973-2008 [circles; $\mathrm{m} \mathrm{s}^{-1}(10 \mathrm{yr})^{-1}$ ]: (a) weather stations and (b) WASWind; surface westerly (easterly) trends are indicated by red (blue) circles, and their magnitudes are shown by the size of circles below each panel. The WASWind vector wind changes are superimposed in (b).

(Tokinaga and Xie 2011a). This dataset has been constructed from ship-observed winds and wind-wave heights in ICOADS. The spurious upward trends due to anemometer height increase make it difficult to identify long-term changes in marine surface wind. The WASWind product substantially reduces such spurious trends by a stability-dependent height correction for measured winds and using wind-wave height to estimate surface wind speed. Not only does this surface wind product successfully reproduce major modes of seasonalto-decadal variability, but its trend patterns are also in good agreement with SLP and satellite-based wind measurements for the recent decades. Circles in Fig. 2 compare June-October zonal wind changes over the Maritime Continent obtained from weather stations and linearly interpolated WASWind on coastal grid points near these weather stations. The former data are available at the Global Surface Hourly database of the NOAA National Data Centers for 1973-2008. Although WASWind tends to underestimate surface easterly trends at coastal stations of the Indian subcontinent, the two datasets are in broad agreement, capturing easterly trends over Sumatra Island, Malaysia and islands off east Australia, and westerly trends over the western equatorial Pacific for the recent 36 years. Interestingly, the vector winds in WASWind display a divergence trend over the Maritime Continent with easterly trends over the eastern equatorial Indian Ocean and westerly trends over the western equatorial Pacific, consistent with the weakened Walker circulation associated with the 1976/77 climate regime shift (Deser and Phillips 2006, and references therein). These features illustrate the utility of WASWind for climate change analysis over this region.

To use the WASWind wind stress as an atmospheric forcing for ocean models, all missing values are filled by the following procedure. We first apply the same linear interpolation for the WASWind monthly anomaly fields as in ICOADS, and then compute the empirical orthogonal functions (EOFs) of the interpolated anomaly field each for zonal and meridional components over the global domain, using only grid boxes that contain monthly anomaly for more than $30 \%$ of the total months for January 1950-December 2009. Top EOF modes accounting for $95 \%$ of the total variance are used to reconstruct a new anomaly field with reduced observational noise. Because this anomaly field still has missing values in the high-latitude Southern Ocean, the wind stress data of the National Centers for Environmental Prediction (NCEP)-National Center for Atmospheric Research (NCAR) reanalysis (Kalnay et al. 1996) are merged south of $30^{\circ} \mathrm{S}$ by averaging with the reconstructed WASWind field. Finally, the climatological wind stresses are added to the reconstructed wind stress anomalies. This reconstructed wind stress field effectively excludes unrealistic spatiotemporal outliners. The same reconstruction method with EOFs is applied for the WASWind zonal and meridional wind fields used in the present study. Trend patterns of the interpolated surface wind and wind stress do not change largely from those in the noninterpolated versions.

\section{c. Bias-corrected expendable bathythermographs}

Subsurface ocean temperatures are obtained from the expendable bathythermograph (XBT) profiles in the Enhanced Ocean Data Assimilation and Climate Prediction (ENACT) archive version 3 (EN3) available at the Met Office (UKMO) Hadley Centre. XBTs were developed in the early 1960s but are known to have a time-varying warm bias due to changes in the fall rate of their probes. We analyze only bias-corrected XBT profiles in EN3 (Wijffels et al. 2008), and construct a $4^{\circ}$ longitude-latitudegridded monthly mean dataset of subsurface temperature for 1963-2009. All temperature profiles are trimmed using 
basically the same quality control as used for ICOADS. Thermocline depth is defined as the depth of the maximum vertical temperature gradient. Data coverage of our gridded XBT dataset is reasonably well over the tropical Indo-Pacific, except for the central Pacific. Trends in temperature and thermocline depth are calculated only if data are available at least for $75 \%$ of the analysis period.

\section{d. Land precipitation}

A $0.5^{\circ}$ longitude-latitude gridded monthly mean dataset is available at the University of Delaware from 1900 to 2008. This precipitation dataset has been constructed from rain gauge observations with climatologically aided interpolation (Willmott and Robeson 1995). We analyze this dataset for 1950-2008. As a cross check, we use noninterpolated rain gauge observations for 1950-99 from the Association of Southeast Asian Nations (ASEAN) Climatic Atlas Project (ACAP) data, provided by the Japan Meteorological Agency (JMA). The ACAP data have been shown to realistically capture rainfall variability over the Maritime Continent (Chang et al. 2005).

\section{e. SST and nighttime marine air temperature}

SST is one of the most fundamental and important variables to measure climate change. We analyze the ICOADS SSTs with the climatological 3.5 standard deviation quality control. To examine possible uncertainties in SST warming pattern in section 5, we also use the following four SST reconstructions: HadISST1 $\left(1^{\circ} \times 1^{\circ}\right)$, ERSST v3b $\left(2^{\circ} \times 2^{\circ}\right)$, the 4.5-sigma quality-controlled ICOADS SSTs $\left(4^{\circ} \times 4^{\circ}\right)$ measured by all methods (bucket-sampling, engine-room intake, hull sensors, etc.), and only by the bucket sampling. We choose the bucketsampling SSTs because this measurement method has commanded a moderate spatial coverage by VOS throughout the study period. By contrast, the engine-intake SSTs have significant time-varying biases with strong regionality (Kent and Taylor 2006). Note that all the above SST reconstructions have applied no bias adjustment between different methods of in situ SST measurements for the study period (1950-2009).

As another cross check for the reconstructed SST trends, we calculate trends in nighttime marine air temperature (NMAT) obtained from ICOADS $\left(4^{\circ} \times 4^{\circ}\right)$ and the Meteorological Office Historical Marine Air Temperature (MOHMAT; Rayner et al. 2003) version 4 $\left(5^{\circ} \times 5^{\circ}\right)$, a parameter less affected by changes in observational methods and the daytime heat island effect of ships. Whereas the former NMAT is constructed with the ICOADS nighttime observation flag and no bias correction, MOHMAT defines night as the period between one hour after sunset and one hour after sunrise and applies a simplified height correction. Despite the differences in definition of night and correction method, the two NMAT datasets show similar warming patterns over the global ocean.

For all SST trend maps in section $5 \mathrm{~b}$ we calculate trends from the 5-yr mean anomalies to suppress sampling errors especially in data-sparse regions of the bucket SST during 2000s. For each dataset, the trend is calculated only on grid boxes that contain more than 10 five-year means and then scaled to the 59-yr trend.

\section{f. Reanalysis products}

To compare with in situ observations, we use precipitation and surface wind stress from the 40-yr European Centre for Medium Range Weather Forecasting (ECMWF) Reanalysis (ERA-40; Uppala et al. 2005) for 1958-2001 and subsurface ocean temperature and sea surface height from the ECMWF operational ocean analysis-reanalysis system (ORA-S3; Balmaseda et al. 2008) for 1963-2009. ORA-S3 is forced by the ERA-40 surface fluxes for about $85 \%$ of the reanalysis period (before June 2002). Thus changes in the ORA-S3 subsurface temperature are generally consistent with those in the ERA-40 wind stress.

\section{g. Models}

To examine the dynamical wind effect on regional patterns of oceanic change, an ocean GCM and a linear reduced gravity shallow water model are used. The ocean GCM is based on the Modular Ocean Model version 3 (Pacanowski and Griffies 2000). Details of the model settings are as follows: resolution is 2.5 degrees in horizontal and 25 levels in vertical. Near the equator the meridional grid spacing is smoothly changed to 0.5 degrees to resolve equatorial waves. The model covers a near-global domain from $65^{\circ} \mathrm{S}$ to $65^{\circ} \mathrm{N}$. This ocean GCM with similar settings successfully reproduces not only intraseasonal to interannual variabilities of dynamical and thermodynamical features in the tropical IndianPacific oceans (Ogata 2009) but also the significant weakening of the equatorial Atlantic cold tongue over the last six decades (Tokinaga and Xie 2011b). The model is first forced by climatological wind stress for 28 years, and then driven by the WASWind monthly mean wind stress from January 1950 to December 2009. SST is restored to the observed monthly mean value of ERSST v3b with a 30-day time scale. Thus the surface heat flux is calculated from the SST restoring. Surface salinity is also restored with the 30-day time scale to the observed monthly climatology. Sponge layers are applied poleward of $62^{\circ} \mathrm{N}-\mathrm{S}$.

We also use a 1.5-layer reduced gravity shallow water model of the stratified ocean, hereafter titled the Reduced 
Gravity Model (RGM). The upper and lower layers of the model are separated by an interface that approximates the sharp tropical thermocline separating the warm surface waters from the cold waters of the deep ocean. Motion in the upper layer is driven by the applied anomalous wind stresses whereas the lower layer is assumed motionless and infinitely deep. The upper-layer ocean dynamics are described by the linear reduced-gravity form of the shallow-water equations (McGregor et al. 2007). The associated response of the ocean is characterized by the vertical displacement of the thermocline, and the horizontal components of upper-layer flow velocity. Sea level is translated from the thermocline depth anomaly using a linear relationship between the two parameters by following Timmermann et al. (2010)'s procedure. The model has a $1^{\circ}$ resolution and is configured for the lowmidlatitude Indo-Pacific Ocean $\left(51^{\circ} \mathrm{S}\right.$ and $51^{\circ} \mathrm{N}, 40^{\circ} \mathrm{E}$ and $60^{\circ} \mathrm{W}$ ). This model is also forced by the WASWind monthly mean wind stresses from January 1950 to December 2009.

In addition, we analyze surface wind stress and sea level changes in the "Climate of the 20th century experiments" from 16 coupled GCMs [Bjerknes Center for Climate Research (BCCR) model, version 2.0 (BCM2.0); the Canadian Centre for Climate Modelling and Analysis (CCCma) Coupled General Circulation Model, version 3.1 T47 (CGCM3.1_T47); Geophysical Fluid Dynamics Laboratory Climate Model version 2.0 (GFDL CM2.0); GFDL CM2.1; Goddard Institute for Space Studies Atmosphere-Ocean Model (GISS-AOM); GISS Model E-H (GISS-EH); GISS Model E-R (GISS-ER); Flexible Global Ocean-Atmosphere-Land System Model gridpoint version 1.0 (FGOALS-g1.0); Model for Interdisciplinary Research on Climate 3.2, high-resolution version (MIROC3.2\{hires\}); MIROC3.2, mediumresolution version MIROC3.2(medres); Meteorological Institute of the University of Bonn, ECHO-G Model (MIUB ECHO-G); Max Planck Institute (MPI) ECHAM5; Meteorological Research Institute Coupled General Circulation Model, version 2.3.2 (MRI CGCM2.3.2); NCAR Community Climate System Model, version 3.0 (CCSM3.0); UKMO third climate configuration of the Met Office Unified Model (HadCM3); and UKMO Hadley Centre Global Environmental Model version 1 (HadGEM1)] in CMIP3 database. We produce multimodel ensemble means of surface wind stress and sea level height by averaging 46 ensemble members from the 16 coupled GCMs and estimate their centennial trends for 1900-99.

\section{h. Trend analysis}

We estimate long-term trends and their statistical significance with the Sen median slope (Sen 1968) and the Mann-Kendall test (Kendall 1975), respectively, both of which are nonparametric methods less affected by outliers sometimes contained in observations. If the linear trend and Student's $t$ test are applied for the same data, our conclusions do not change. To capture a full cycle of ENSO with a peak typically in December, all annual means are defined as the 12-month mean from June to the following May. The analysis period is basically from June 1950 to May 2009, except for subsurface temperature that starts in 1963 and land precipitation that ends in 2008. All trends are calculated using only well-sampled grid boxes where the temporal mean data (annual, seasonal or monthly means) are available for more than $75 \%$ of the analysis period, to reduce sampling errors. To improve the readability of the ICOADS maps, weighted spatial smoothing (5 points in longitude and 3 points in latitude) is applied for trend patterns after computing their significance.

\section{Tropical Pacific}

This section examines regional patterns of tropical Pacific climate change through a synthesis of in situ observations and the ocean GCM simulation.

\section{a. Atmospheric changes}

Figure 3 compares annual mean changes in marine cloudiness, SLP, surface wind, and SST for 1950-2008. As highlighted by Norris (2005) and Deser et al. (2010), changes in marine cloudiness exhibit a significant increase over the central tropical Pacific and decrease over the western tropical Pacific. This spatial pattern is negatively correlated with that of SLP change with a significant decrease over the central tropical Pacific and increase over the Maritime Continent. Consistent with the patterns of observed SLP and cloudiness change our bias-corrected WASWinds exhibit increased surface wind convergence over the central tropical Pacific with westerly trends to the west and easterly trends to the east. A significant weakening of northeast trade winds represents a weakened subtropical high with reduced meridional SLP gradient over the Northwest Pacific around $10^{\circ}-25^{\circ} \mathrm{N}$. All these observational results support a reduction in the Walker and Hadley circulation over the tropical Pacific.

In contrast, the regional patterns of ICOADS SST trend cannot be used to explain those of cloudiness, SLP, and surface wind changes (Fig. 3d). The ICOADS SST displays intense warming over the eastern and western equatorial Pacific and reduced warming over the central tropical Pacific with no significant change in zonal gradient of equatorial SST on the basin scale. This differs from a typical pattern of SST anomalies during the El Niño with a weakened Walker circulation. One possible hypothesis is that the SST warming pattern does not play a primary 


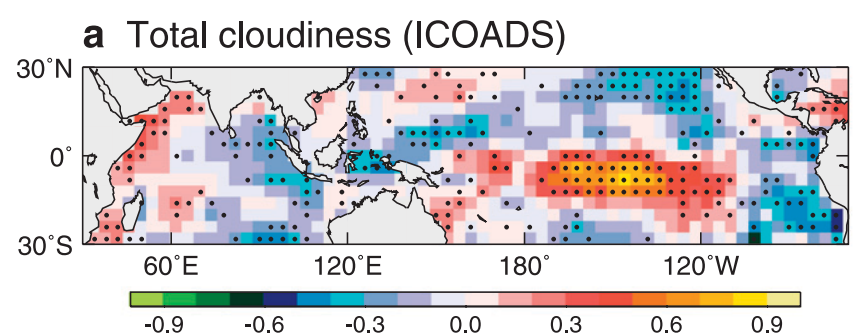

b SLP (ICOADS)

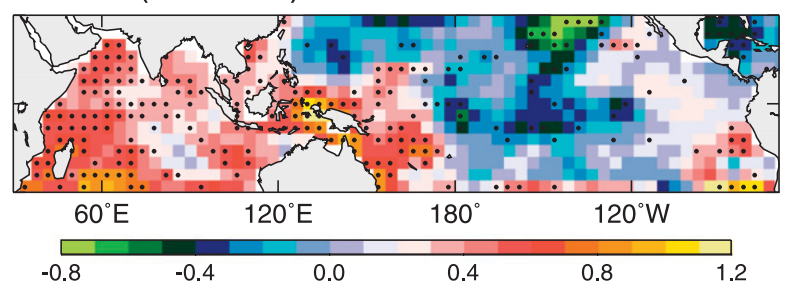

d SST (ICOADS)

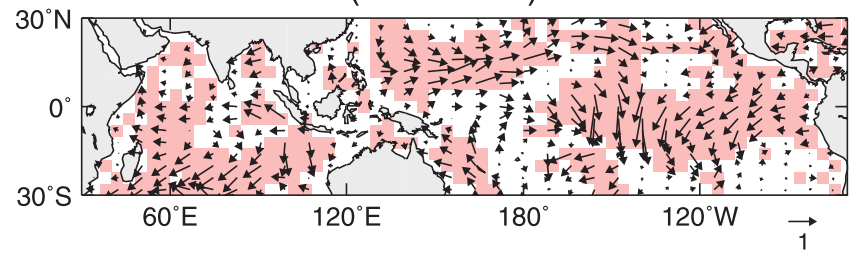

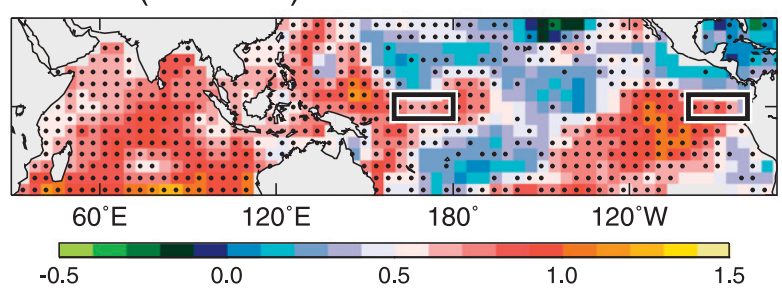

FIG. 3. Annual-mean changes for 1950-2008: (a) marine cloudiness [okta (59 yr) ${ }^{-1}$ ], (b) SLP [hPa (59 yr) ${ }^{-1}$, (c) surface wind [m s ${ }^{-1}$ $(59 \mathrm{yr})^{-1}$ ], and (d) SST [ ${ }^{\circ} \mathrm{C}(59 \mathrm{yr})^{-1}$ ]. Significant trends at the $90 \%$ confidence level are marked with dots for cloudiness, SLP, and SST (highlighted for surface wind). Cloudiness, SLP, and SST (surface wind) data are based on ICOADS (WASWind). Black rectangles denote regions used to average subsurface temperature profiles in the eastern and western equatorial Pacific in Fig. 4.

role in tropospheric circulation changes (Held and Soden 2006). Recent studies show that atmospheric GCMs without any change in zonal SST gradient simulate the slowdown of the Walker circulation due to increased atmospheric static stability under global warming (Gastineau et al. 2009; Ma et al. 2012). Another possibility is that the SST uncertainty is still too large to definitively identify the SST warming pattern because of time-varying biases in historical SST measurements. If this is true, we cannot deny the possibility that weakened zonal SST gradient through Bjerknes feedback has slowed down the Walker circulation over the past decades. We will discuss this possibility in section 5 by comparing several SST and NMAT reconstructions.

\section{b. Subsurface temperature change}

Whereas poor correspondence is observed between SST and atmospheric changes, subsurface ocean temperature displays more consistent changes with those in equatorial zonal wind stress. Figure 4 shows annual mean changes in subsurface temperature averaged in the eastern $\left(80^{\circ}-100^{\circ} \mathrm{W}, 4^{\circ} \mathrm{S}-4^{\circ} \mathrm{N}\right)$ and western $\left(160^{\circ} \mathrm{E}-180^{\circ}, 4^{\circ} \mathrm{S}-\right.$ $4^{\circ} \mathrm{N}$ ) equatorial Pacific obtained from bias-corrected XBTs during 1963-2008. Subsurface temperature in the western equatorial Pacific exhibits a significant cooling at 200-m depth, indicating a shoaling of the climatological thermocline in response to the overlying surface westerly trends (Fig. 3c). This shoaling of the equatorial western Pacific thermocline is consistent with the independent results of Vecchi et al. (2006), Han et al. (2006), and Yang and Wang (2009). Supporting the subsurface cooling, isotope records collected from corals also suggest a similar shoaling of the mean nutricline and an increase in primary productivity in the western tropical Pacific since the mid-to-late 1970s (Williams and Grottoli 2010). Ocean temperature of the western equatorial Pacific shows a significant warming in the top to $100-\mathrm{m}$ layer, but this near-surface warming is only about one-half of that in the eastern equatorial Pacific. The annual mean change in near-surface $(5-20 \mathrm{~m})$ temperature difference

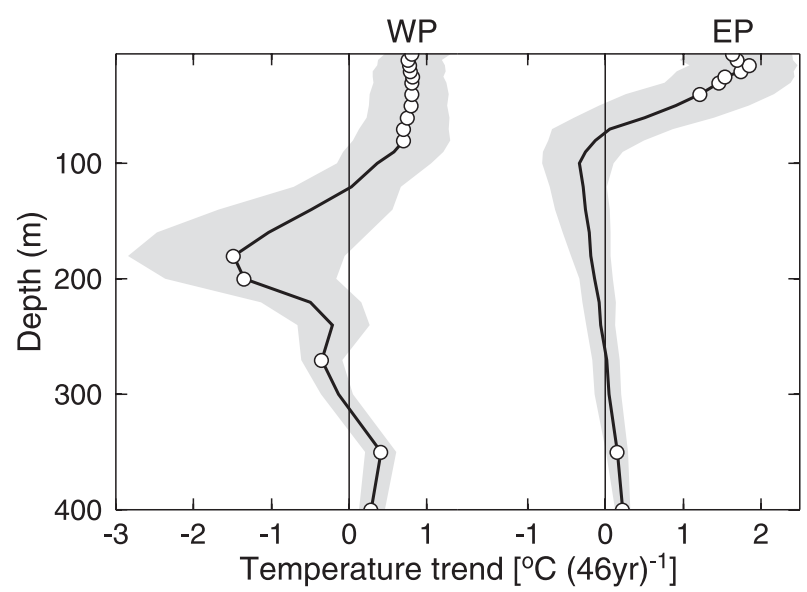

FIG. 4. Annual-mean subsurface temperature change $\left[{ }^{\circ} \mathrm{C}\right.$ $(46 \mathrm{yr})^{-1}$ ] averaged in the eastern $\left(\mathrm{EP} ; 80^{\circ}-100^{\circ} \mathrm{W}, 4^{\circ} \mathrm{S}-4^{\circ} \mathrm{N}\right)$ and western (WP; $160^{\circ} \mathrm{E}-180^{\circ}, 4^{\circ} \mathrm{S}-4^{\circ} \mathrm{N}$ ) equatorial Pacific for $1963-$ 2008. Trends exceeding the $90 \%$ confidence level are marked with open circles. The gray shading indicates $90 \%$ confidence intervals based on the Sen median slope method. Subsurface temperature data are based on bias-corrected XBTs of EN3. 


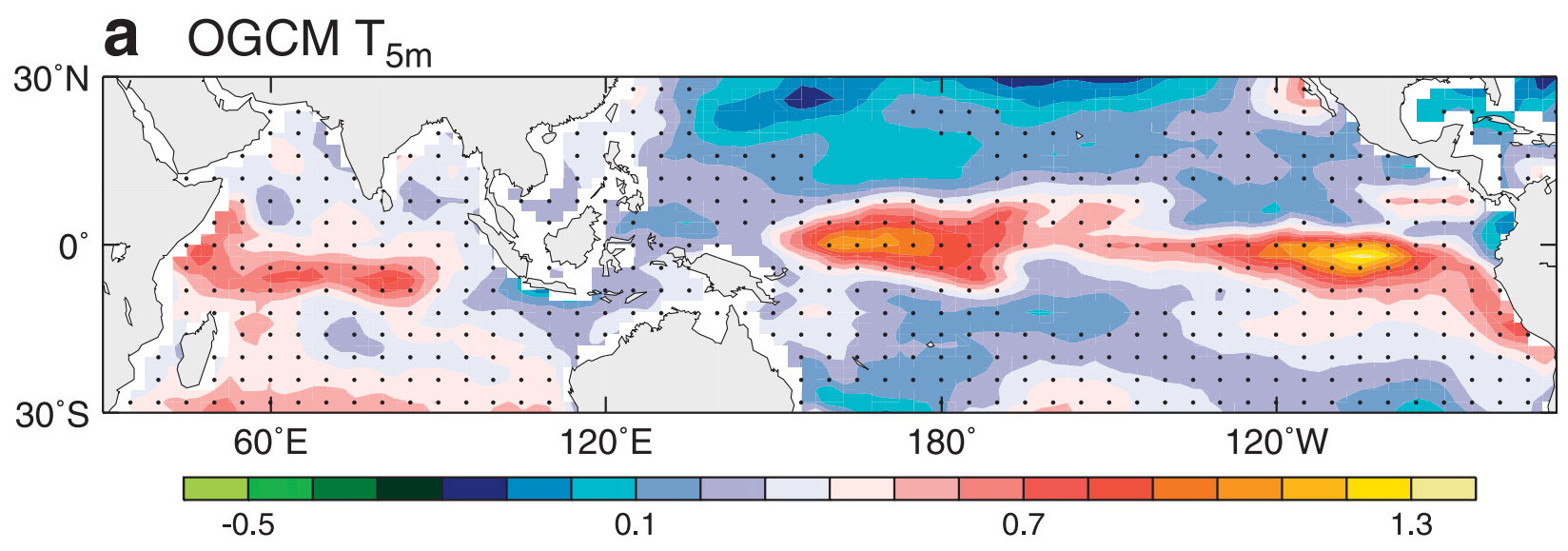

\section{b OGCM Thermocline depth}

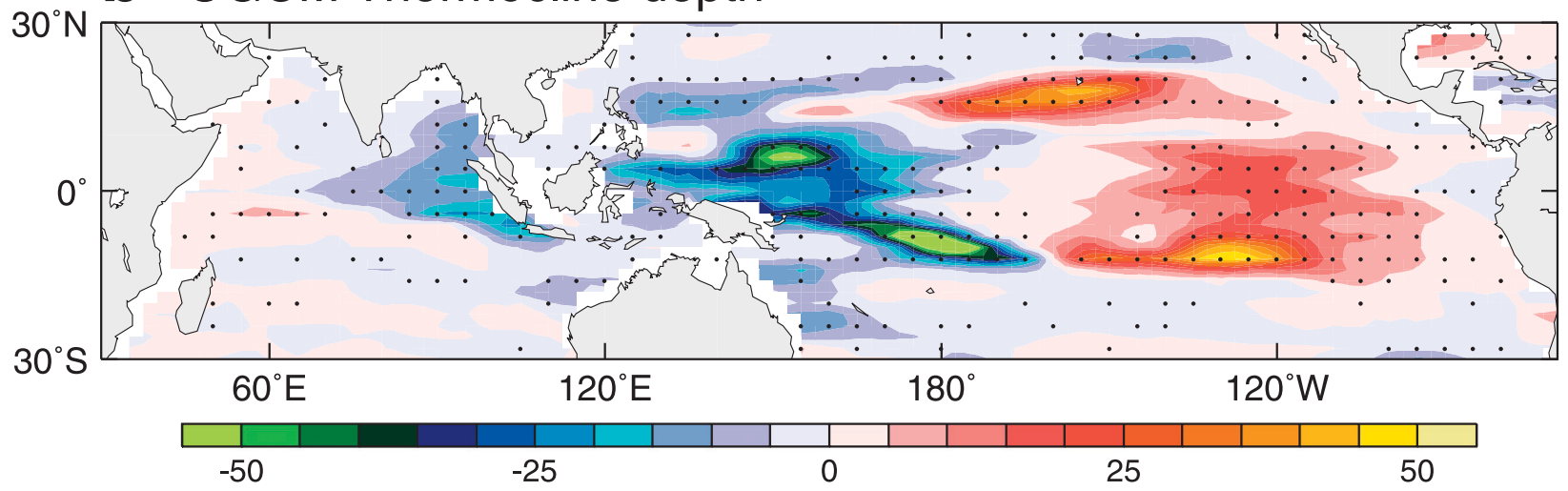

C OGCM SSH

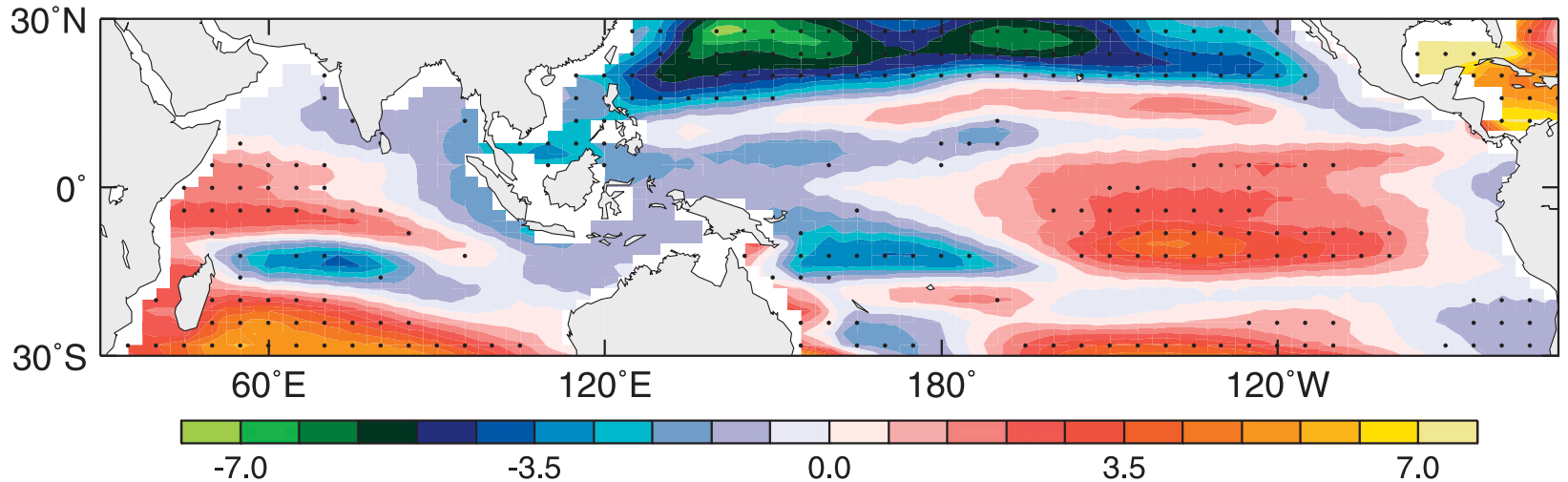

FIG. 5. As in Fig. 3, but for changes in the ocean GCM forced by WASWind: (a) the 5 -m temperature $\left[{ }^{\circ} \mathrm{C}(59 \mathrm{yr})^{-1}\right]$, (b) thermocline depth $\left[\mathrm{m}(59 \mathrm{yr})^{-1}\right]$, and (c) sea surface height $\left[\mathrm{cm}(59 \mathrm{yr})^{-1}\right]$. The domain average $\left(30^{\circ} \mathrm{E}-60^{\circ} \mathrm{W}, 30^{\circ} \mathrm{S}-30^{\circ} \mathrm{N}\right)$ of sea level is removed. Trends exceeding the $90 \%$ confidence level are marked with dots.

between the two regions reaches $+0.79^{\circ} \mathrm{C}$ per 46 years (significant at $p=0.1$ ), indicating a weakening of the eastwest thermal contrast in the ocean mixed layer. This result looks inconsistent with the change in equatorial zonal SST gradient in Fig. 3d but may explain the observed westerly trend in zonal wind stress $\left(+0.7 \times 10^{-2} \mathrm{~N} \mathrm{~m}^{-2}(46 \mathrm{yr})^{-1}\right.$, significant at $p=0.1$ ) averaged over the western tropical Pacific $\left(160^{\circ} \mathrm{E}-160^{\circ} \mathrm{W}, 10^{\circ} \mathrm{S}-10^{\circ} \mathrm{N}\right)$. The reduced zonal gradient in the mixed layer temperature may be more reliable than the analyzed SST change because XBT measurements are stable at least in the mixed layer where the depth biases are minimum. As mentioned previously, 

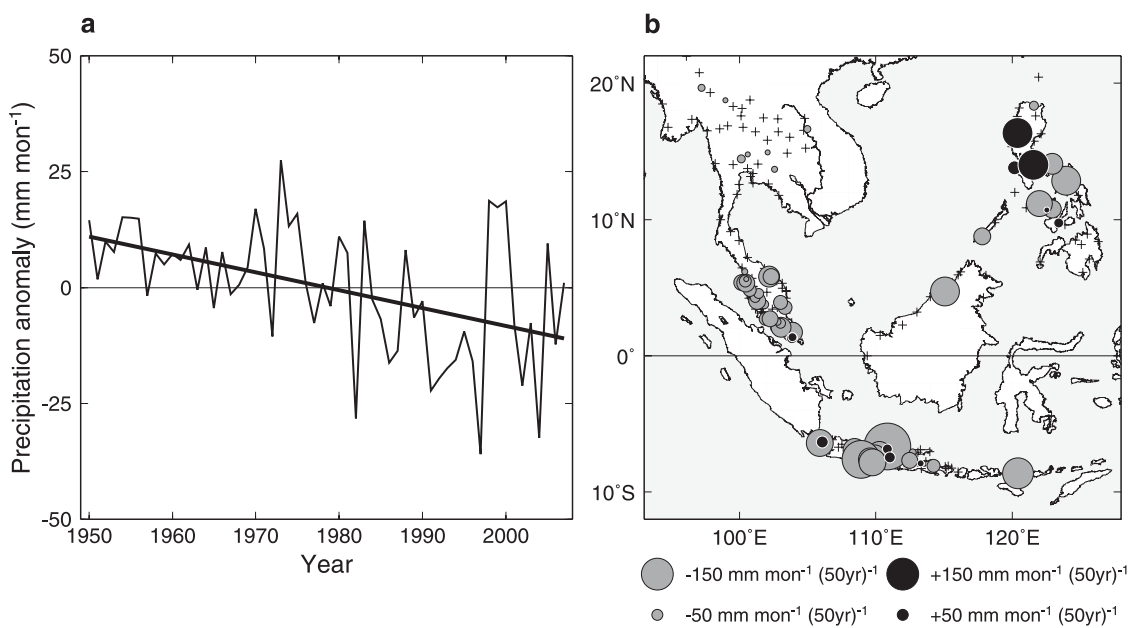

FIG. 6. (a) Time series of land precipitation anomaly (thin line; $\mathrm{mm} \mathrm{month}^{-1}$ ) averaged over the Maritime Continent $\left(80^{\circ}-150^{\circ} \mathrm{E}, 20^{\circ} \mathrm{S}-20^{\circ} \mathrm{N}\right)$. The thick line indicates linear regression of the precipitation anomaly. The precipitation data is based on the gridded monthly product provided by University of Delaware. (b) Land precipitation changes obtained from the ACAP rain gauge observations from 1950 to $1999\left[\mathrm{~mm} \mathrm{month}^{-1}(50 \mathrm{yr})^{-1}\right]$. The decreasing (increasing) trends exceeding the $95 \%$ confidence level are indicated with gray (black) circles, and their magnitudes are shown by the size of circles below the panel.

the reliability of the analyzed SST changes will be further discussed in section 5 of this manuscript.

Interestingly, the ocean GCM forced by WASWind simulates a tongue-like warming of the 5-m temperature in the equatorial Pacific with a reduced zonal contrast (Fig. 5a), despite the fact that the SST is restored to the observed monthly mean value of ERSST with no significant change in the zonal gradient. The reduced zonal contrast is more obvious in the spatial distribution of the thermocline depth and sea level changes (Figs. 5b,c), with a shoalinglowering trend in the western tropical Pacific and deepening-rising trend in the eastern tropical Pacific. This flattened thermocline across the tropical Pacific resembles the future projection by CMIP3 models under the global warming A1B scenario (Fig. 12 of Vecchi and Soden 2007).

\section{Maritime Continent and tropical Indian Ocean}

The Maritime Continent, the climatological center of atmospheric deep convection, is a key region to changes in the Walker circulation linking the tropical Pacific and Indian Oceans. This section investigates precipitationcloudiness changes over the Maritime Continent and their connection with regional patterns of tropical Indian Ocean climate change.

\section{a. Precipitation change over the Maritime Continent}

Consistent with the slowdown of the Walker circulation, significant decreasing trends in marine cloudiness are widespread from the eastern tropical Indian Ocean through Indonesia to the western tropical Pacific (Fig. 3). Peaks of the decreased marine cloudiness and increased SLP are observed near New Guinea, as well as divergence trends in surface wind.

Figure 6a shows the time series of annual mean land precipitation averaged over the Maritime Continent $\left(80^{\circ}-\right.$ $150^{\circ} \mathrm{E}, 20^{\circ} \mathrm{S}-20^{\circ} \mathrm{N}$ ) obtained from the gridded product based on rain gauge observations for 1950-2008. This time series successfully captures anomalously dry (wet) years associated with the strong El Niño (La Niña) such as 1982 and 1997 (1973 and 1999), indicating a good representation of Walker circulation variability. Consistent with the decreased marine cloudiness, a significant downward trend is evident in land precipitation over the last six decades. The Sen trend slope for this time series is -0.43 $\pm 0.2 \mathrm{~mm} \mathrm{mon}^{-1} \mathrm{yr}^{-1}$ over the period 1950-2008 at $p=$ 0.05 , which corresponds to a $15 \%$ reduction of the annual mean climatology. While this gridded precipitation product fills in missing values with an optimal statistical procedure (Willmott and Robeson 1995), most of the raw rain gauge observations collected from the ASEAN countries show similar decreasing trends with a regional peak over Indonesia (Fig. 6b), where the significant divergence trends in surface wind are observed. The areaaveraged trend from a total of the 283 rain gauge stations record a $0.35 \mathrm{~mm}$ month $^{-1} \mathrm{yr}^{-1}$ decrease over the period 1950-99. Moreover, we obtain an estimated precipitation decrease of $0.4 \mathrm{~mm}$ month $^{-1} \mathrm{yr}^{-1}$ over the period 1950-2008 from a typical value of cloudiness change $\left[\sim-0.3\right.$ okta $\left.(59 \mathrm{yr})^{-1}\right]$ around the Maritime 

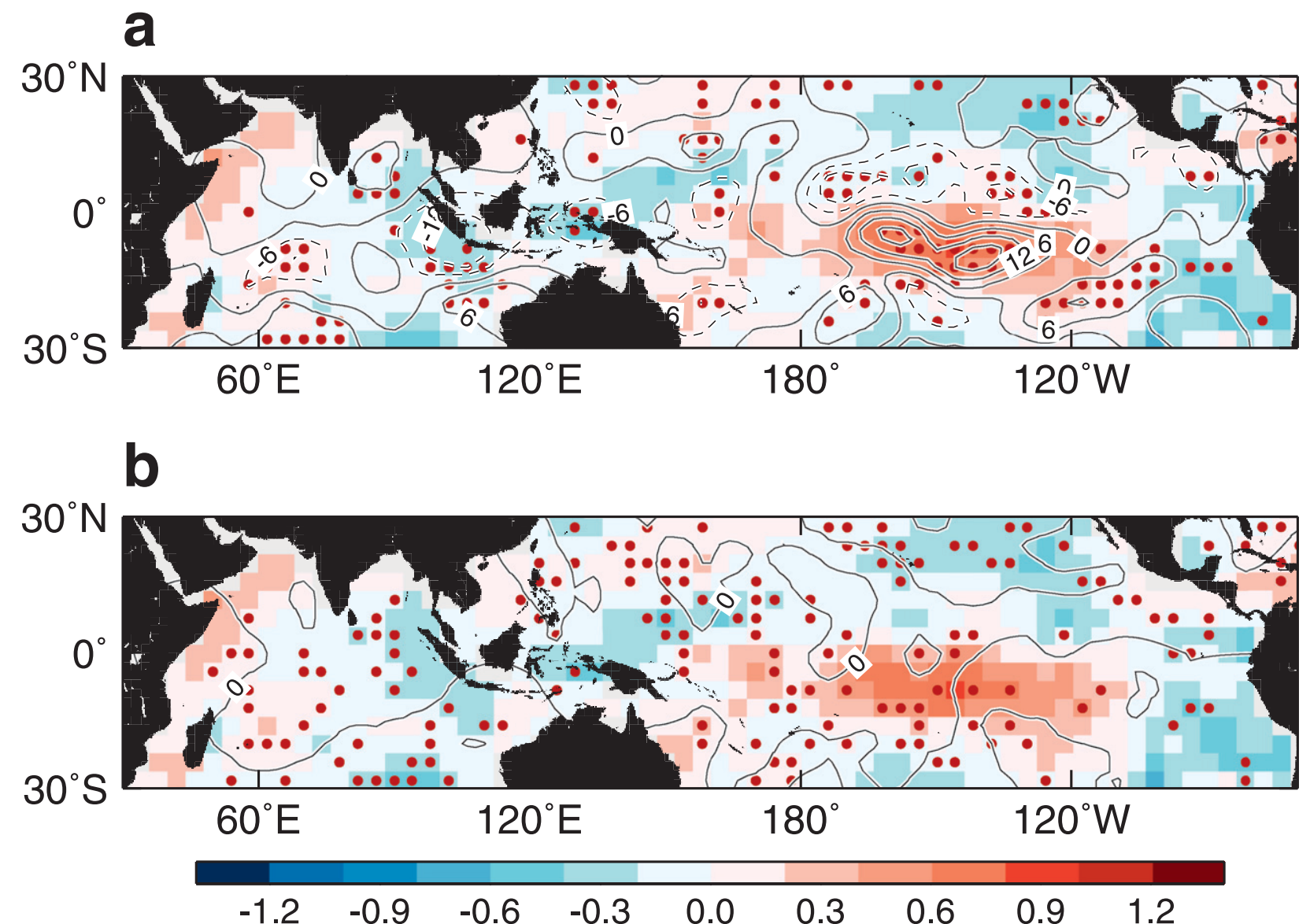

FIG. 7. As in Fig. 3, but for changes in surface moisture-flux convergence [contours at $6 \times 10^{-6} \mathrm{~g} \mathrm{~kg}^{-1} \mathrm{~s}^{-1}$ (59 yr) $)^{-1}$ d due to effects of (a) surface wind and (b) surface air specific humidity. Surface wind and specific humidity data are based on WASWind and ICOADS, respectively. Trends exceeding the $90 \%$ confidence level are marked with red dots. The 59-yr changes in ICOADS cloudiness are superimposed [shading in okta $(59 \mathrm{yr})^{-1}$ ].

Continent (Fig. 3a) using the linear regression coefficient in Fig. 1 ( $\left.+77.8 \mathrm{~mm} \mathrm{month}^{-1} \mathrm{okta}^{-1}\right)$. The magnitudes of these precipitation decreases are comparable to that in the gridded land precipitation product in Fig. 6a.

The cloudiness-precipitation changes should be associated with those in moisture flux convergence. Because a large amount of moisture convergence occurs in the atmospheric boundary layer, we examine changes in surface moisture-flux convergence expressed by $-\boldsymbol{\nabla} \cdot(q \mathbf{V})$, where $q$ is near-surface atmospheric specific humidity from ICOADS, and $\mathbf{V}$ is surface wind vector from WASWind. The surface moisture-flux convergence, $-\nabla \cdot(q \mathbf{V})$, can be decomposed into the four terms as follows:

$$
\begin{aligned}
-\nabla \cdot(q \mathbf{V})= & -\nabla \cdot(\bar{q} \overline{\mathbf{V}})-\nabla \cdot\left(\bar{q} \mathbf{V}^{\prime}\right) \\
& -\nabla \cdot\left(q^{\prime} \overline{\mathbf{V}}\right)-\nabla \cdot\left(q^{\prime} \mathbf{V}^{\prime}\right),
\end{aligned}
$$

where $\left(^{-}\right)$and $\left(^{\prime}\right)$ denote the annual climatology and anomaly, respectively. The first term on the right-hand side is the climatological moisture-flux convergence, the second term denotes the moisture-flux convergence due to the wind effect, and the third term denotes the moisture-flux convergence due to the moisture effect. The last term is negligible. The 59-yr changes in the second and third terms are compared in the contour plots of Fig. 7, superimposed on the marine cloudiness changes (shading in Fig. 7). The wind-induced change in moisture-flux convergence, $-\nabla \cdot\left(\bar{q} \mathbf{V}^{\prime}\right)$, exhibits similar spatial patterns to the cloudiness change, with regions of suppressed (enhanced) moisture-flux convergence corresponding to regions of decreased (increased) cloudiness such as over the eastern tropical Indian Ocean and the Maritime Continent (central tropical Pacific). These patterns resemble epoch differences in cloudiness and surface wind convergence between 1977-2000 and 1950-76 revealed by Deser and Phillips (2006). The magnitudes of the wind-induced change are roughly an order of magnitude larger than the moisture-induced changes, 

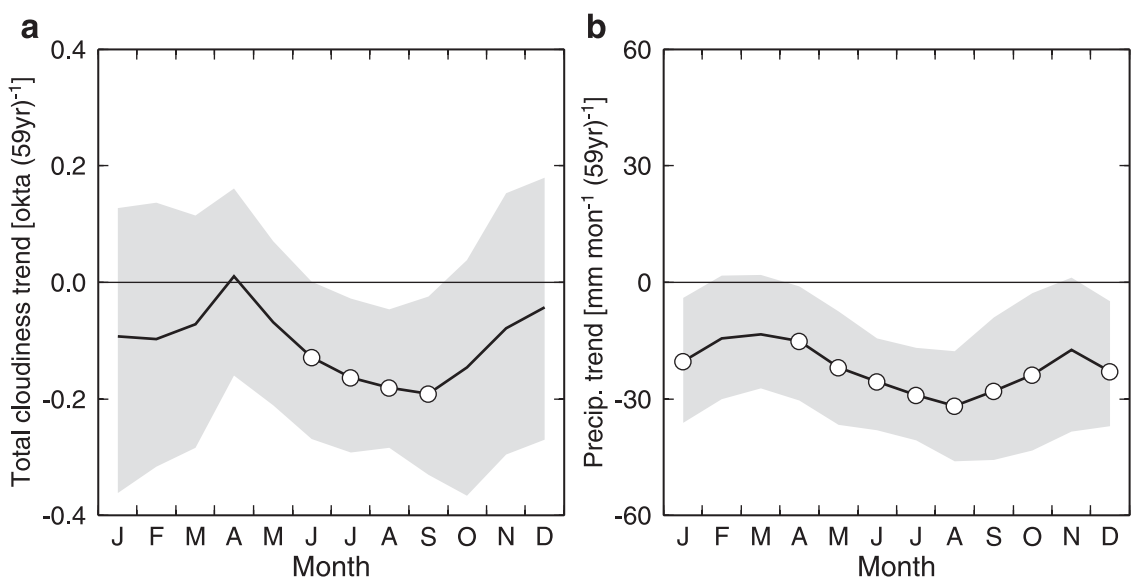

FIG. 8. Seasonal evolutions of monthly trends for 1950-2008 as a function of calendar month: (a) ICOADS cloudiness [okta $(59 \mathrm{yr})^{-1}$ ] and (b) the University of Delaware land precipitation $\left[\mathrm{mm}\right.$ month $\left.^{-1}(59 \mathrm{yr})^{-1}\right]$ averaged over the Maritime Continent $\left(80^{\circ}-150^{\circ} \mathrm{E}, 20^{\circ} \mathrm{S}-20^{\circ} \mathrm{N}\right)$. Monthly mean data are smoothed with a 3-month running average to suppress subseasonal variabilities. Trends exceeding the $95 \%$ confidence level are marked with open circles. The gray shading indicates $95 \%$ confidence intervals based on the Sen median slope method.

$-\nabla \cdot\left(q^{\prime} \overline{\mathbf{V}}\right)$, indicating that the wind-induced change dominates in the pattern formation of cloudiness change over the last six decades. Such a dynamical role of atmospheric circulation is found in the CMIP3 models, but the thermodynamic change due to the increased atmospheric moisture rather plays a primary role in the models (Emori and Brown 2005; Held and Soden 2006; Vecchi and Soden 2007). This is probably because the
CMIP3 models tend to underestimate the dynamical component of the Walker circulation changes compared to the observations, while increases in atmospheric moisture are comparable between the CMIP3 models and observations. For instance, a comparison between the CMIP3 multimodel ensemble mean and observations indicates that the simulated change in east-west SLP gradient over the tropical Indo-Pacific corresponds to only
Indian Ocean

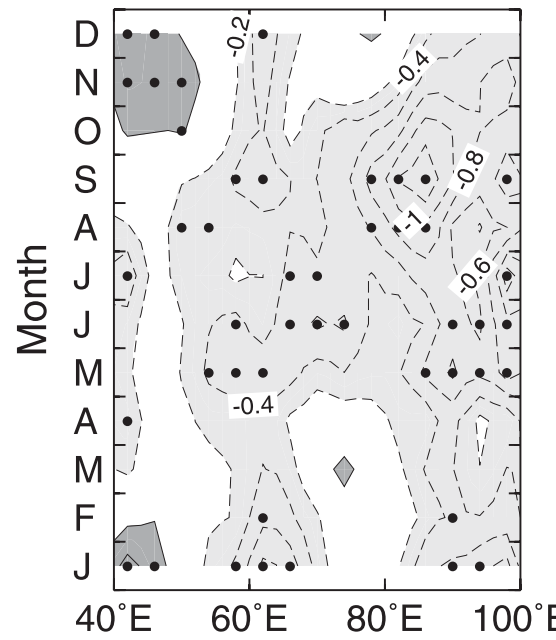

Pacific

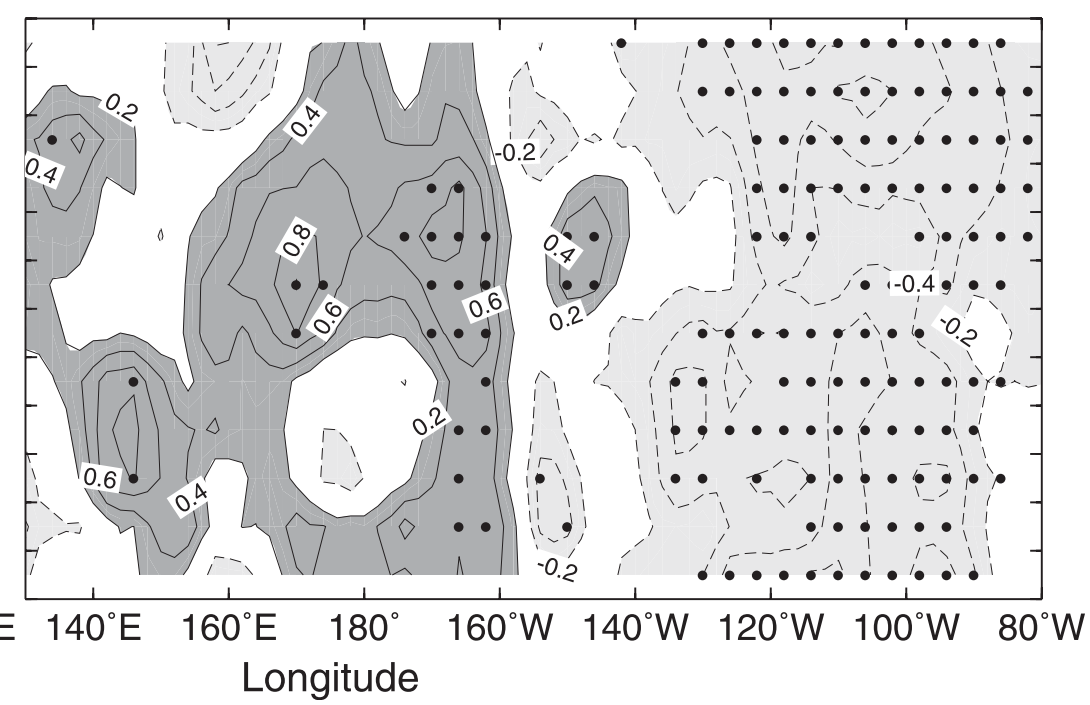

FIG. 9. Seasonal evolution of monthly zonal wind trend for 1950-2008 as a function of longitude and calendar month [dark shade $>$ $0.2 \mathrm{~m} \mathrm{~s}^{-1}(59 \mathrm{yr})^{-1}$; light $<-0.2 \mathrm{~m} \mathrm{~s}^{-1}(59 \mathrm{yr})^{-1}$; contours at $0.2 \mathrm{~m} \mathrm{~s}^{-1}(59 \mathrm{yr})^{-1}$ ]. Monthly mean data are smoothed with a 3-month running average to suppress subseasonal variabilities. Trends exceeding the $90 \%$ confidence level are marked with dots. The zonal wind data are based on WASWind. 


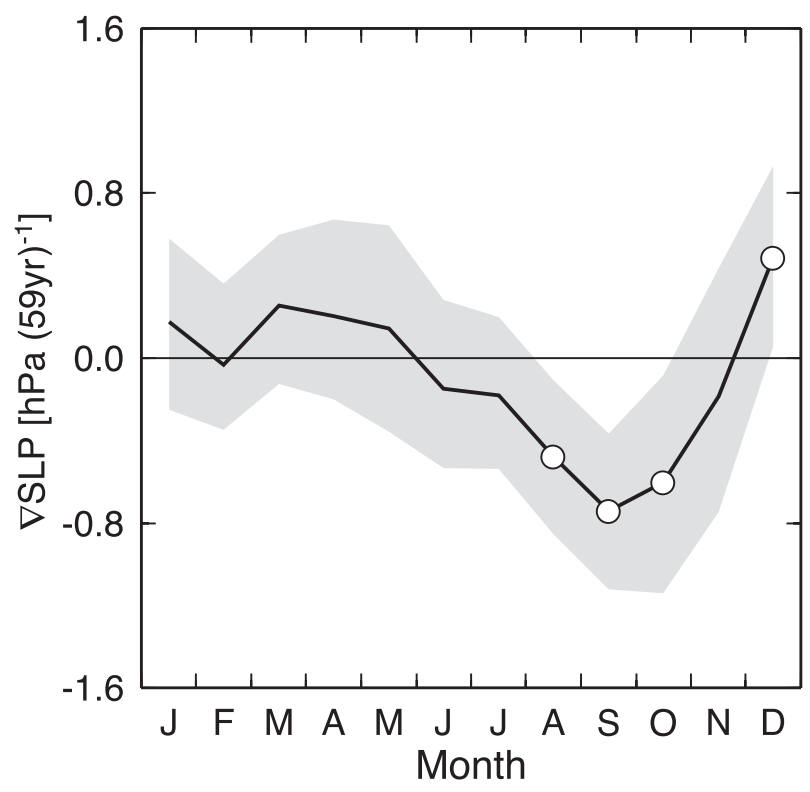

FIG. 10. As in Fig. 8, but for zonal SLP difference [hPa $(59 \mathrm{yr})^{-1}$ ] between the western $\left(40^{\circ}-60^{\circ} \mathrm{E}, 2^{\circ} \mathrm{S}-2^{\circ} \mathrm{N}\right)$ and eastern $\left(85^{\circ}-105^{\circ} \mathrm{E}\right.$, $\left.2^{\circ} \mathrm{S}-2^{\circ} \mathrm{N}\right)$ tropical Indian Ocean. Trends exceeding the $90 \%$ confidence level are marked with open circles. The SLP data are based on ICOADS.

about $20 \%$ of the observed change during the twentieth century (CMIP3 multimodel ensemble mean: -0.10

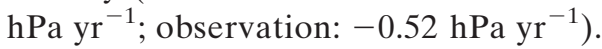

Next we examine the seasonality of observed trends over the Maritime Continent. The observed trends in marine cloudiness and land precipitation exhibit a similar seasonality with strongest reduction during JuneOctober exceeding the 95\% confidence level (Fig. 8). Consistent with the seasonality of reduced cloudiness and suppressed atmospheric convection, the surface divergence trend over the Maritime Continent also peaks during June-October, largely due to a strong seasonality of the significant easterly trends over the equatorial Indian Ocean (Fig. 9). The surface easterly trend starts to develop in June, peaks in August-September, and decays in December, supporting a strong seasonality of positive IOD-like SST trend in HadISST (Cai et al. 2009a). The seasonality of easterly trends is also generally in good agreement with a seasonal development of trends in zonal SLP gradient across the equatorial Indian Ocean showing negative trends from June to November with a significant peak in August-October (Fig. 10). Over the central equatorial Pacific, on the other hand, the surface convergence seems to be significant throughout the year but a seasonality of the surface westerly trend over $160^{\circ} \mathrm{E}-160^{\circ} \mathrm{W}$ is similar to that of the cloudiness/ precipitation trend over the Maritime Continent (Fig. 9). This common seasonality among observed trends of SLP, wind velocity, convergence, and cloud/precipitation gives us confidence in the results. The following section focuses on boreal summer-to-fall season, when changes are most pronounced over the tropical Indian Ocean.

\section{b. June-November changes in the tropical Indian Ocean}

Figure 11 shows the spatial distributions of observed changes averaged in June-November for 1950-2008. Over the tropical Indian Ocean, the zonal dipole pattern of cloudiness change is stronger than in the annual mean (Fig. 3a). Surface wind changes are easterly on the equator, blowing from the negative into positive pole of

\section{a Total cloudiness (ICOADS)}

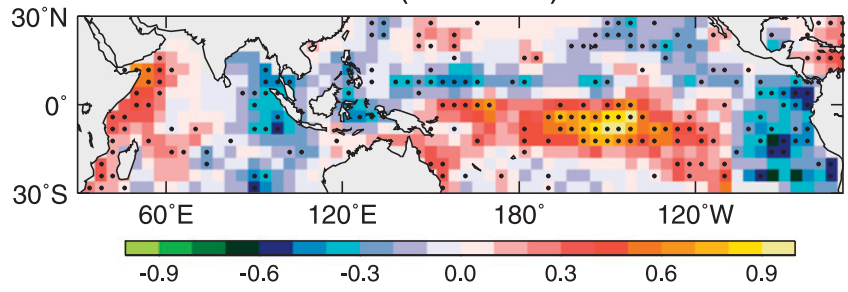

c Surface wind (WASWind)

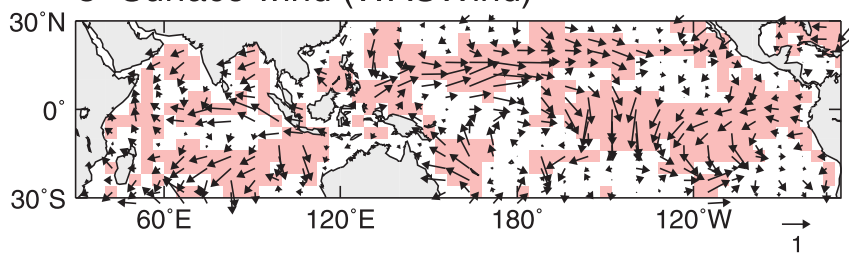

b SLP (ICOADS)

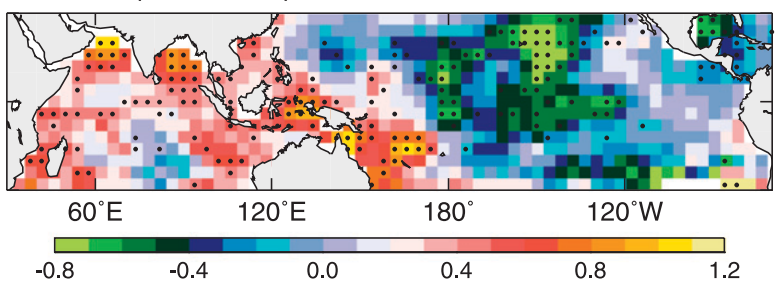

d SST (ICOADS)

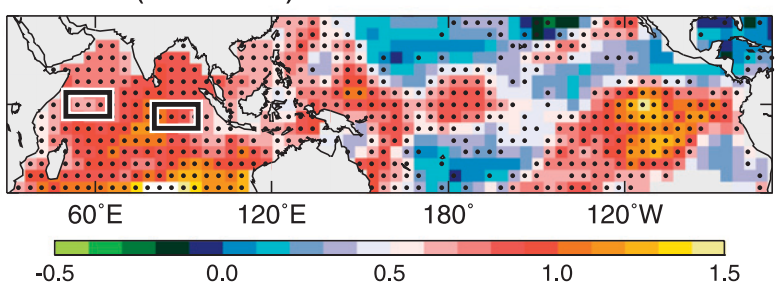

FIG. 11. As in Fig. 3, but for June-November mean changes. Black rectangles denote regions used to average subsurface temperature profiles in the eastern and western equatorial Indian Ocean in Fig. 12. 
the cloud dipole (Figs. 11a,c). Consistent with the equatorial easterly winds, SLP changes are somewhat larger over the eastern than western tropical Indian Ocean (Fig. 11b). Local maxima of the increased SLP are also observed over the Arabian Sea and the Bay of Bengal along the coast of South Asia, associated with a weakening of the Indian summer monsoon (Tokinaga and Xie 2011a). The SST change displays a significant basinwide warming with local maxima in the central Indian Ocean and off the west coast of Australia (Fig. 11d). Reduced SST warming off the west coast of Sumatra Island is consistent with enhanced coastal upwelling expected from the intensified southeasterly winds. Cai et al. (2009a) suggest that this suppressed warming off the Sumatra coast is most pronounced during September-November, supporting the strong seasonality of easterly trends over the eastern equatorial Indian Ocean (Fig. 9). The zonal contrast of the equatorial SST warming, however, is not significant, despite significant and physically consistent changes in cloudiness, surface wind, and SLP.

Similar to the tropical Pacific, the surface wind changes leave a significant imprint on subsurface ocean temperature in the tropical Indian Ocean (Han et al. 2006). The mean ocean thermocline in the equatorial Indian Ocean has a mean depth of around $100 \mathrm{~m}$ and is characterized by a weak zonal tilt, which shoals in the east due to coastal upwelling off the Sumatra coast during boreal summer-to-fall season only. This shoaling in the east enables IOD variability as the near-surface temperature becomes sensitive to changes in surface wind and subsurface temperature (Saji et al. 1999; Xie et al. 2002). During this season, the subsurface temperature changes at around 100-m depth in the eastern and western equatorial Indian Ocean indicate a thermocline shoaling in the east and deepening in the west in response to the surface easterly trends on the equator (Fig. 12). As a result, the mean thermocline is zonally flatter and the subsurface temperature change averaged in $5-50-\mathrm{m}$ depth is about $0.9^{\circ} \mathrm{C}$ warmer in the western than eastern equatorial Indian Ocean for 1963 2008. These observed changes in subsurface temperature are reproduced reasonably well by CMIP3 models that simulate a slowdown of the Walker circulation during the last half century (Cai et al. 2009b; Du and Xie 2008).

Next we examine how the trend in zonal thermal contrast has developed for recent decades. Figure 13 shows the time series of zonal wind anomaly averaged over the equatorial Indian Ocean $\left(50^{\circ}-100^{\circ} \mathrm{E}, 4^{\circ} \mathrm{S}-4^{\circ} \mathrm{N} ; U_{\mathrm{EQ}}\right)$, zonal SLP difference between the western $\left(40^{\circ}-60^{\circ} \mathrm{E}, 2^{\circ} \mathrm{S}-2^{\circ} \mathrm{N}\right)$ and eastern $\left(85^{\circ}-105^{\circ} \mathrm{E}, 2^{\circ} \mathrm{S}-2^{\circ} \mathrm{N}\right)$ tropical Indian Ocean ( $\nabla S L P)$, and the Dipole Mode indices (DMIs; Saji et al. 1999) defined by a zonal difference in subsurface temperature averaged in $80-100-\mathrm{m}$ depth, SST, and marine cloudiness anomalies between the tropical western

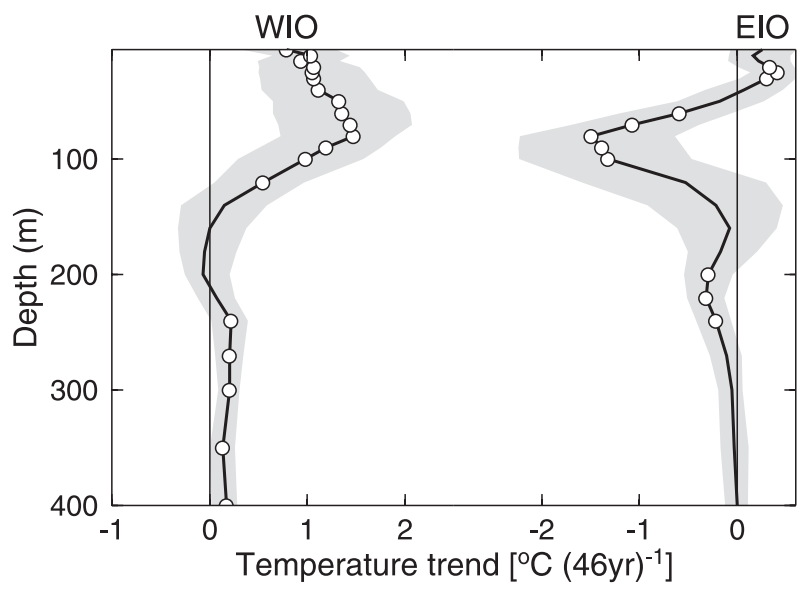

FIG. 12. As in Fig. 4, but for June-November mean subsurface temperature change averaged in the southeastern $\left(\mathrm{EIO} ; 80^{\circ}-95^{\circ} \mathrm{E}\right.$, $\left.8^{\circ} \mathrm{S}-0^{\circ}\right)$ and western $\left(\mathrm{WIO} ; 50^{\circ}-65^{\circ} \mathrm{E}, 4^{\circ} \mathrm{S}-4^{\circ} \mathrm{N}\right)$ tropical Indian Ocean.

$\left(50^{\circ}-70^{\circ} \mathrm{E}, 10^{\circ} \mathrm{S}-10^{\circ} \mathrm{N}\right)$ and southeastern $\left(90^{\circ}-110^{\circ} \mathrm{E}\right.$, $10^{\circ} \mathrm{S}-0^{\circ}$ ) Indian Ocean. Atmospheric and oceanic time series are averaged in August-September and AugustNovember, respectively, to consider a longer persistence of ocean anomalies and increase data samplings of ocean subsurface temperature. All the time series capture the major IOD events such as in 1963, 1994, and 1997 and highly correlate with each other on interannualto-decadal time scales. The time series of $U_{\mathrm{EO}}$ and $\nabla$ SLP show strong decadal variability in 1960 s, followed by a steady downward trend over the subsequent decades (Figs. 13a,b). The decadal variability in the 1950-60s is also captured by DMIs obtained from SST and cloudiness, and partly by the subsurface-DMI (Figs. 13c-e), suggesting a decadal modulation of the interannual IOD variability (Annamalai et al. 2005; Ashok et al. 2004). While no significant trend in the SST-DMI over the last six decades, both the subsurface- and cloudiness-DMIs exhibit significant upward trends after 1970, at +2.1 $\pm 1.0^{\circ} \mathrm{C}$ and $+0.6 \pm 0.27$ okta for $1970-2006(p=0.01)$, respectively. These significant trends after 1970 are also remarkable in $U_{\mathrm{EO}}$ and $\nabla \mathrm{SLP}$ with an opposite sign, indicative of the reduction in the Walker circulation.

\section{c. Simulated sea level change in the tropical Indian Ocean}

Regional patterns of Indian Ocean sea level change are still controversial among recent studies because of limited tide gauge observations and large variance in ocean model response to different wind stress products (Han et al. 2010; Timmermann et al. 2010). As presented in this study, our bias-corrected WASWind product can provide long wind stress data consistent with the changes in SLP, cloudiness, and subsurface temperature obtained 
a

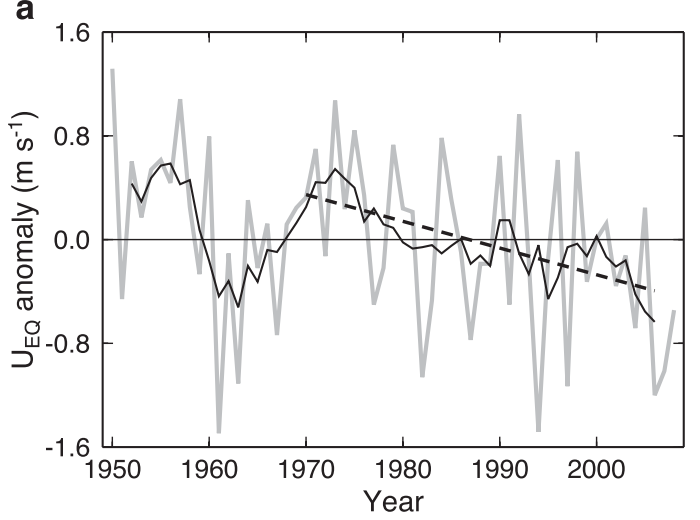

C

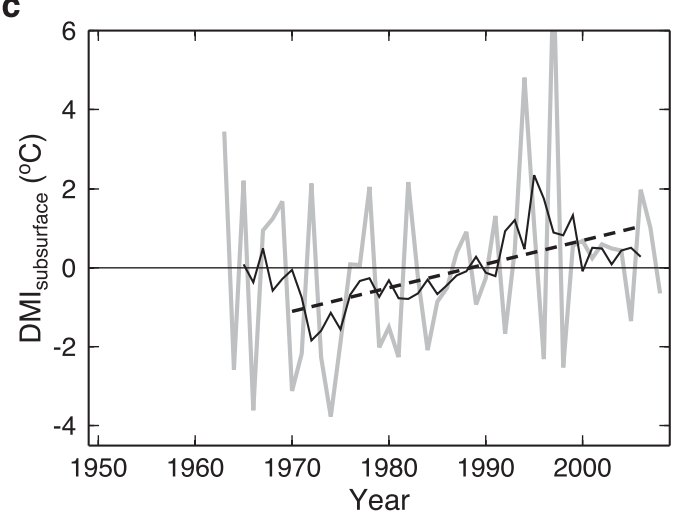

e

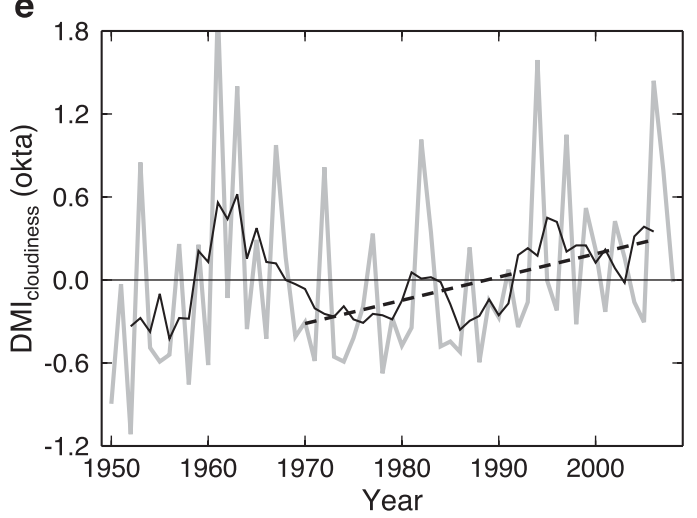

b

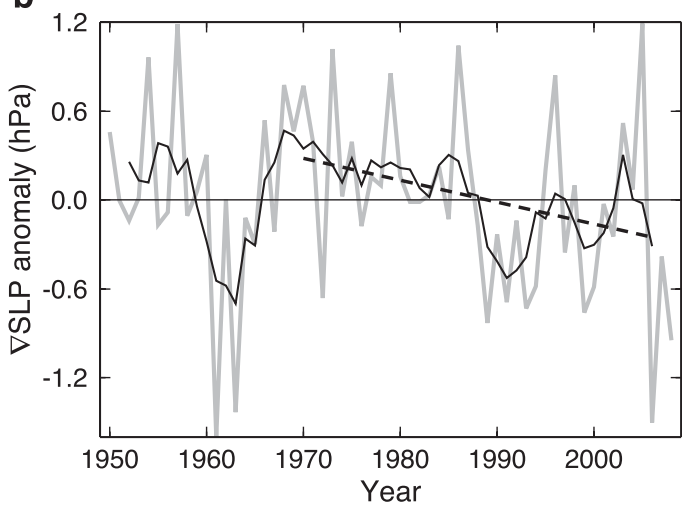

d

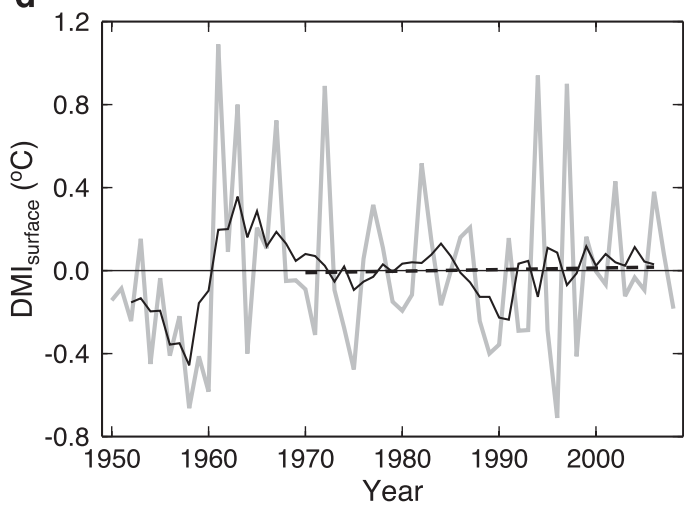

FIG. 13. Time series of (a) zonal wind anomaly $\left(\mathrm{m} \mathrm{s}^{-1}\right.$; WASWind) averaged over the equatorial Indian Ocean $\left(50^{\circ}-100^{\circ} \mathrm{E}, 4^{\circ} \mathrm{S}-4^{\circ} \mathrm{N}\right)$, (b) zonal SLP difference $(\mathrm{hPa}$; ICOADS $)$ between the western $\left(40^{\circ}-60^{\circ} \mathrm{E}, 2^{\circ} \mathrm{S}-2^{\circ} \mathrm{N}\right)$ and eastern $\left(85^{\circ}-105^{\circ} \mathrm{E}, 2^{\circ} \mathrm{S}-2^{\circ} \mathrm{N}\right)$ tropical Indian Ocean, and the DMIs defined by (c) subsurface temperature from 80 - to $100-\mathrm{m}$ depth $\left({ }^{\circ} \mathrm{C}\right.$; bias-corrected XBTs of EN3), (d) SST $\left({ }^{\circ} \mathrm{C}\right.$ ), and (e) marine cloudiness (okta; ICOADS). The gray lines indicate year-to-year time series averaged in August-September (August-November for oceanic indices), superimposed on the 5-yr running average (black line). Dashed lines denote linear regressions of the 5-yr running average for 1970-2006. from independent observations. With this surface wind stress product as a forcing to the RGM and OGCM, we examine dynamical response of sea level in the tropical Indian Ocean. Figure 14 compares patterns of the annual-mean sea level change for 1970-2008 in the RGM and OGCM forced with WASWind, respectively. This 39 -yr period corresponds to when both $U_{\mathrm{EQ}}$ and subsurface-DMI exhibit steady trends (Fig. 13a). The RGM simulates two zonal bands of significant sea level rise in the off-equatorial Indian Ocean, associated with the reduced Ekman pumping and the westward-propagating downwelling Rossby waves forced by the equatorial easterly trends (Fig. 14a). These easterly trends also cause coastal and equatorial upwelling in the eastern equatorial Indian Ocean, lowering sea level there to be balanced by the sea level rise in the off-equatorial Indian Ocean. The OGCM forced with the same wind forcing simulates weaker banded structures due to its coarser horizontal resolution but a more distinct zonal dipole of sea level change than in the RGM (Fig. 14b). These patterns are quite similar to the positive phase of interannual IOD, consistent with the steady easterly wind trend over the equatorial Indian Ocean after 1970 (Fig. 13a). Changes in thermocline depth observed by XBTs show a generally good correspondence to the simulated sea level changes in both RGM and OGCM 
a RGM + WASWind \& XBT (1970-2008)

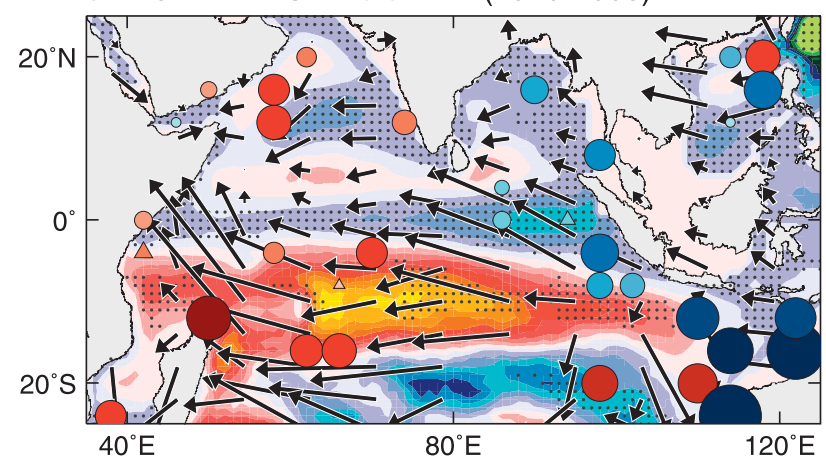

b OGCM + WASWind \& XBT (1970-2008)

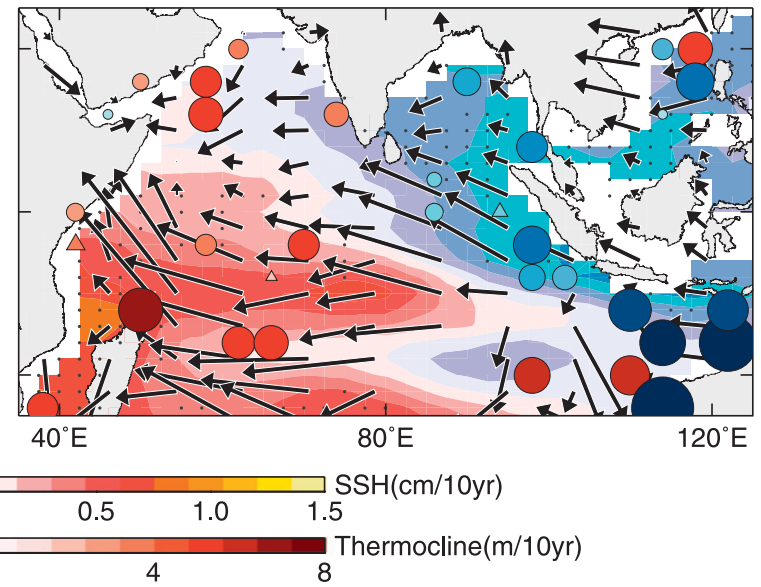

C RGM + WASWind (1950-2008)

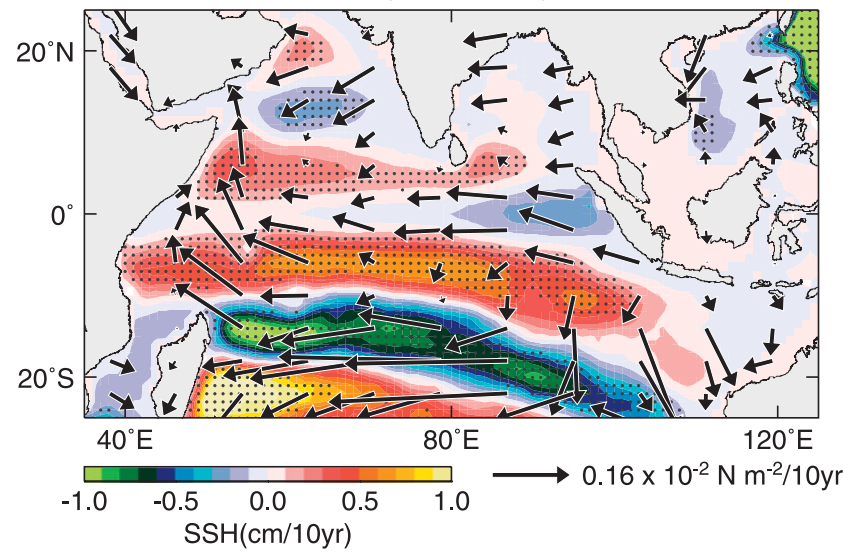

d CMIP3 20C3M (1900-1998)

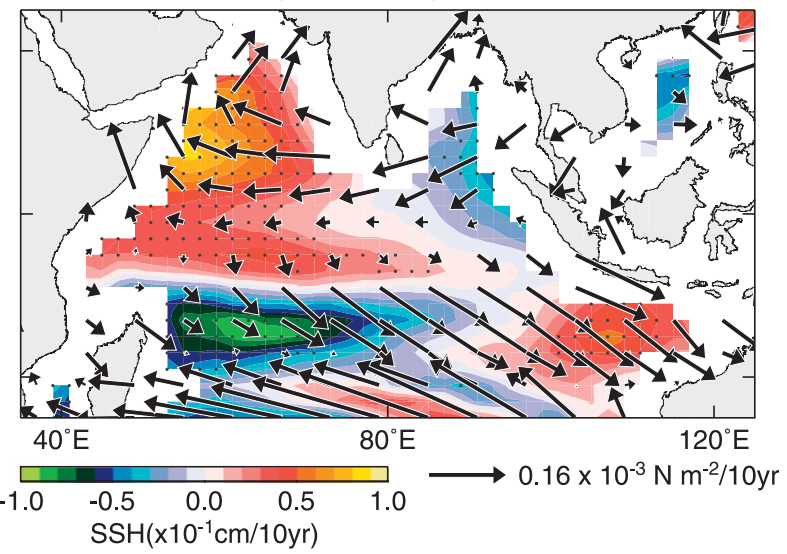

FIG. 14. Changes in annual mean sea level [ $\mathrm{cm}(10 \mathrm{yr})^{-1}$ ] simulated by (a) the RGM and (b) OGCM for 1970-2008, superimposed on changes in surface wind stress [vector; $\mathrm{N} \mathrm{m}^{-2}(10 \mathrm{yr})^{-1}$ ] of WASWind and thermocline depth of bias-corrected XBTs [color in $\mathrm{m}(10 \mathrm{yr})^{-1}$; circles for significant trend at the $90 \%$ confidence level, and triangles for the $88 \%$ confidence level], respectively. (c), (d) As in (a), but for changes in the WASWind wind stress and the RGM sea level for 1950-2008, and changes in the multimodel ensemble means of the CMIP3 model experiments during the twentieth century, respectively. The domain average $\left(30^{\circ}-130^{\circ} \mathrm{E}, 30^{\circ} \mathrm{S}-30^{\circ} \mathrm{N}\right)$ of sea level is removed for all panels.

with a deepening trend in the west and shoaling trend in the east (circles in Figs. 14a,b).

For 1950-2008, the positive IOD-like sea level change is still apparent along with the weaker equatorial easterly wind stresses (Figs. 5c and 14c). Interestingly, the CMIP3 multimodel ensemble mean displays weaker equatorial easterly wind stresses during the twentieth century and a similar corresponding Indian Ocean zonal dipole sea level trend pattern (Fig. 14d), consistent with the positive IOD-like trends in SST and thermocline depth (Cai et al. 2009b). While there is still large uncertainty in projected regional distribution of future sea level change (Christensen et al. 2007), we note that similar patterns of sea level and thermocline changes are reproduced in future projections by CMIP3 models under increased GHG forcing (Du and Xie 2008; Timmermann et al.
2010; Vecchi and Soden 2007; Zheng et al. 2010). This robust pattern in observations and simulations implies that changes observed over the tropical Indian Ocean for the past few decades include the influence of GHG forcing.

\section{Discussion}

With a synthesis of independent in situ datasets and ocean model simulations, the present study has provided robust evidence for the weakening of the Walker circulation and associated oceanic response over the last six decades. The observed changes with a common seasonality are physically consistent with each other over the tropical Indo-Pacific, giving confidence in the results. There are, however, a few issues that have remained 
a ERA40 precipitation

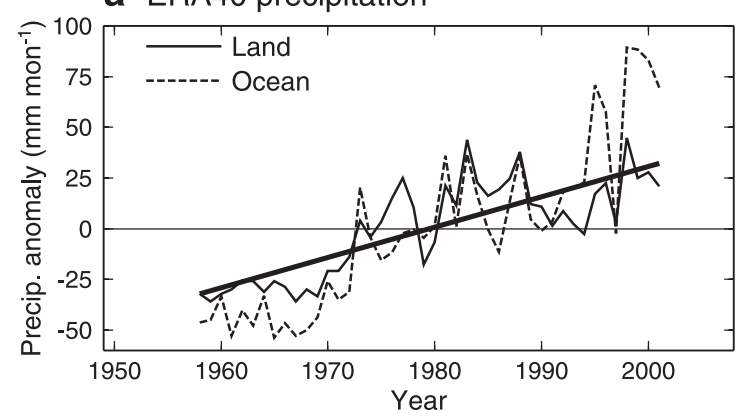

b OGCM SSH + WASWind

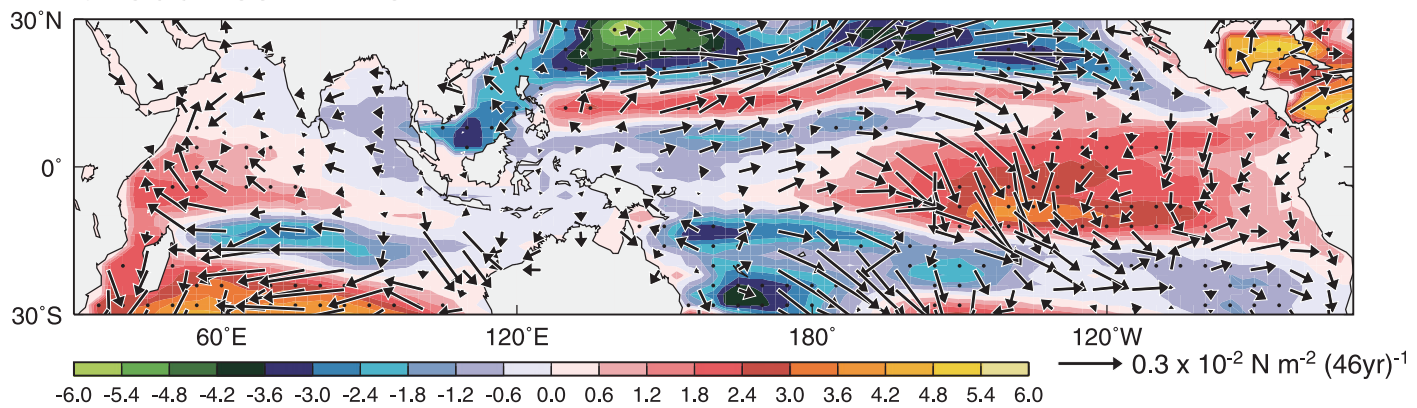

$\begin{array}{lllllllllllllllllllll}-6.0 & -5.4 & -4.8 & -4.2 & -3.6 & -3.0 & -2.4 & -1.8 & -1.2 & -0.6 & 0.0 & 0.6 & 1.2 & 1.8 & 2.4 & 3.0 & 3.6 & 4.2 & 4.8 & 5.4 & 6.0\end{array}$ $\begin{array}{ll}8 & -1.2 \\ \text { SSH trend }\left[\mathrm{cm}(46 \mathrm{yr})^{-1}\right]\end{array}$

c ORA-S3

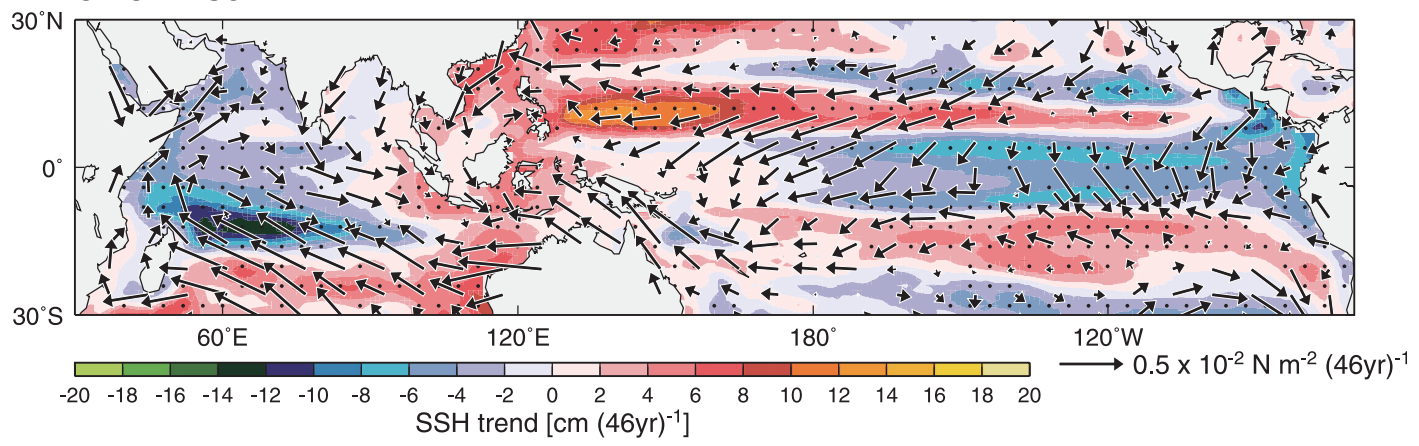

d ORA-S3 (Indian Ocean)

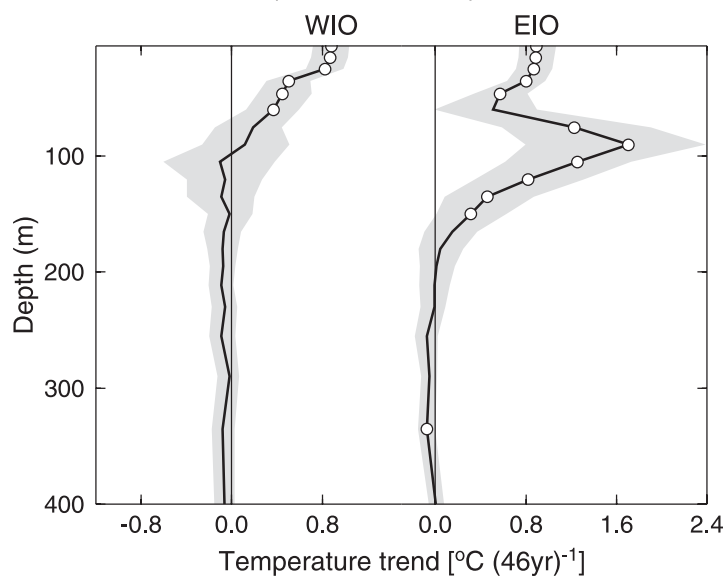

e ORA-S3 (Pacific)

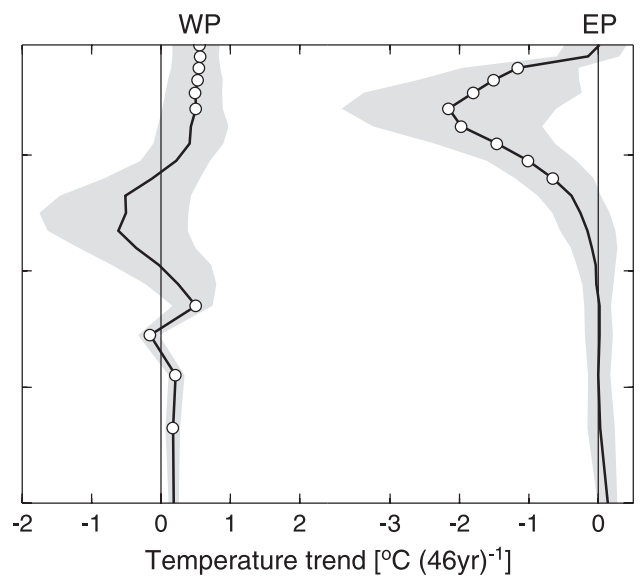

FIG. 15. (a) As in Fig. 6a, but for the ERA-40 precipitation averaged over land (thin solid line) and ocean (dashed line) of the Maritime Continent. The thick line indicates linear regression of the land precipitation. (b) As in Figs. 14a, but for 46-yr changes in the WASWind wind stress and ocean GCM sea level for 1963-2008. (c) As in (b), but for the ORA-S3 wind stress and sea level changes. The domain average $\left(30^{\circ} \mathrm{E}-60^{\circ} \mathrm{W}, 30^{\circ} \mathrm{S}-30^{\circ} \mathrm{N}\right)$ of sea level is removed for (b),(c). (d),(e) As in Figs. 4 and 12, but for ORA-S3 subsurface temperature changes. 
unclear yet. This section discusses two important issues for climate change studies; the use of reanalysis products and uncertainty in warming patterns in widelyused SST reconstructions.

\section{a. Long-term trends in reanalysis products}

As long, user-friendly gridded meteorological records of global coverage, atmospheric reanalysis products obtained from data assimilation are increasingly used for diagnostic studies of climate variability and change. Surface fluxes of momentum, heat, and radiation in the atmospheric reanalyses are often used as atmospheric forcing for ocean GCMs and ocean reanalyses such as ORA-S3 and the Simple Ocean Data Assimilation (SODA; Carton et al. 2000).

Although the self-consistent reanalysis data are useful for understanding of dynamical and thermodynamical mechanisms for climate variability, their long-term trends should be interpreted with caution because of inhomogeneity of observational data assimilated into the reanalysis system (Hagemann et al. 2005; Trenberth et al. 2001; Wu and Xie 2003). For example, a positive drift in global-mean precipitation in 1990s, largely originated in the tropics, is a common error among the major atmospheric reanalysis products, probably due to the instrumental changes in satellite-based atmospheric sounding data (Onogi et al. 2007). The positive drift in precipitation is especially large in ERA-40 that maximally assimilates satellite observations. Figure 15a shows the annual-mean time series of the ERA-40 precipitation averaged over land and ocean grid points of the Maritime Continent. In contrast to the rain gauge observation (Fig. 6), the ERA-40 precipitation suffers from a positive drift over both land and ocean for 1958-2001. The increasing trends over land and ocean are $+1.47 \pm 0.35 \mathrm{~mm} \mathrm{month}^{-1} \mathrm{yr}^{-1}$ and $+2.62 \pm 0.61 \mathrm{~mm} \mathrm{month}^{-1} \mathrm{yr}^{-1}$ over the period 1958-2001 at $p=0.05$, respectively. This discrepancy in precipitation trend from observations suggests that hydrological trends in ERA-40 should be treated with great care.

Associated with the increased precipitation, the Walker circulation has intensified in ERA-40 for the reanalysis period with surface wind convergence over the Maritime Continent and thus surface easterly trends over the western equatorial Pacific and westerly trends over the eastern equatorial Indian Ocean (Yu and Zwiers 2010). We stress that both changes in the ERA-40 precipitation and surface wind over the tropical Indo-Pacific are opposite to those in in situ observations from weather stations and ships. Figure 15c shows the ORA-S3 sea level and wind stress changes for 1963-2008. The strengthening of the Walker circulation is found in the ORA-S3 wind stress field, largely due to ERA-40 trends before 2002 . The ORA-S3 produces La Niña-like and negative IODlike patterns of sea level change in the tropical Pacific and Indian Ocean, respectively, in response to the spurious strengthening of the Walker circulation. Consistent with these sea level changes, the ORA-S3 subsurface ocean temperature displays a significant strengthening of zonal gradient of the mixed layer temperature with relatively larger warming in the western than eastern equatorial Pacific, and in the eastern than western equatorial Indian Ocean (Figs. 15d,e). These changes in the ORA-S3 sea level and subsurface temperature are similar to those in SODA (Trenary and Han 2008) and nearly identical to patterns of sea level change in the ocean GCM (Han et al. 2010) and RGM (Timmermann et al. 2010) forced by the ERA-40 wind stress.

In contrast, surface divergence trends over the Maritime Continent are found in WASWind with weak easterly trends over the equatorial Indian Ocean for the same period (1963-2008) (Fig. 15b), affected by the strong decadal variability during 1960s (Fig. 13). The ocean GCM forced by WASWind exhibits an El Niño-like trend in the tropical Pacific and a positive IOD-like one in the tropical Indian Ocean for this period (Fig. 15b), supported by the bias-corrected XBTs with significant weakening of zonal gradient of the mixed layer temperature in the tropical Indo-Pacific (Figs. 4 and 12). Overall, our findings from independent ocean observations are almost opposite to those in ORA-S3, calling for caution in the use of reanalysis products for studies of tropical climate change.

\section{b. Uncertainty in observed SST trend}

Global SST products have been reconstructed using a variety of SST measurements such as infrared sensors by satellite, thermistors by buoy, and bucket sampling, engine-intake and hull sensors by ships. For example, HadISST1 blends satellite SSTs to ship and buoy observations, but ERSST v3b uses only the in situ sources. Both SST reconstructions successfully capture major modes of climate variability with a wide range of spatiotemporal scales, indicating that observational errors between different measuring methods are not a serious problem for climate variabilities of large amplitudes $\left(\sim 1^{\circ} \mathrm{C}\right.$ or more). On the other hand, this may not be the case for detection of recent SST warming patterns with spatial variations of $0.5^{\circ} \mathrm{C}$ or less, a magnitude on par with time-varying biases and errors with regional variations. Kent and Taylor (2006) report that the engineintake SST is more common in the Pacific than in the Atlantic and it suffers from large time-varying biases before 1990s. 
a ERSST v3b

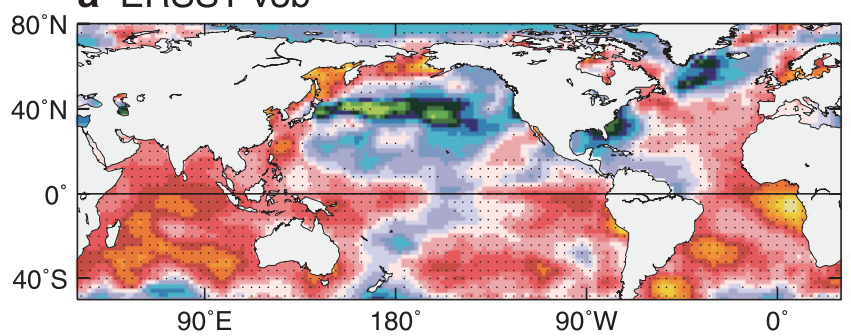

c ICOADS SST (All methods)

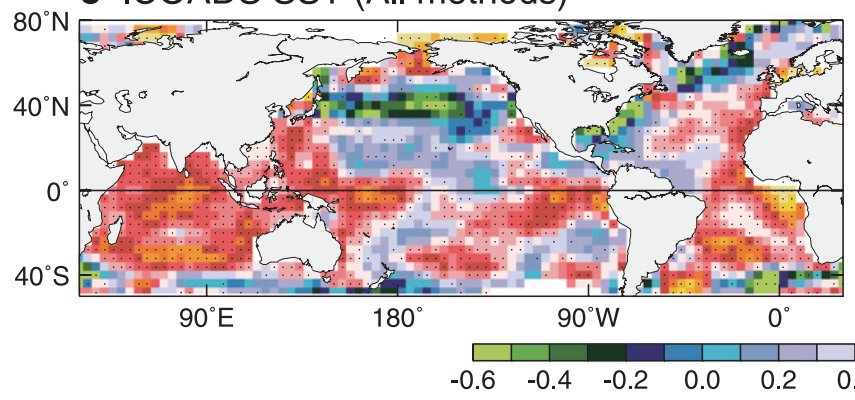

e ICOADS NMAT

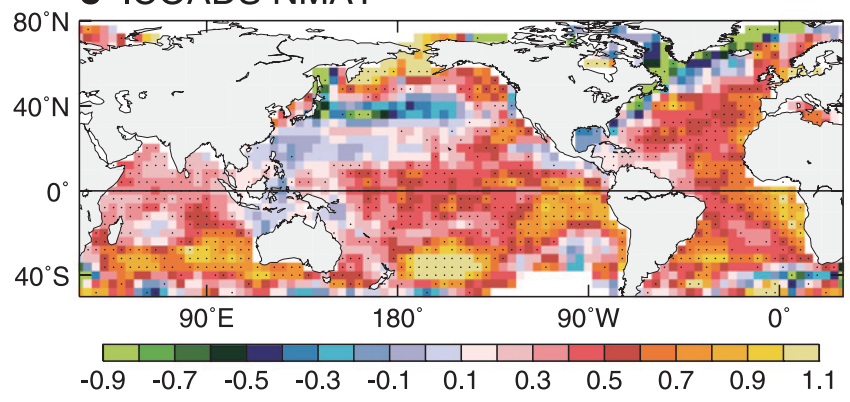

\section{b HadISST1}

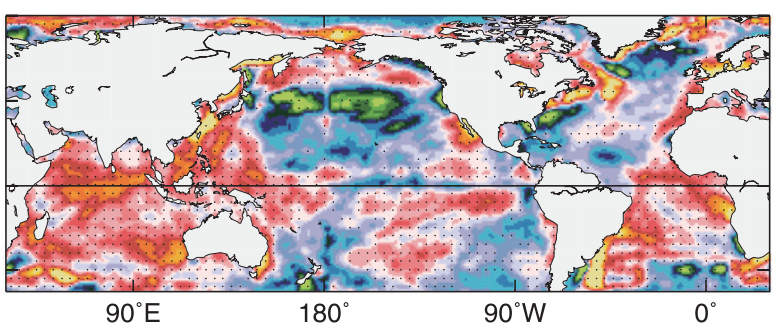

d ICOADS SST (Bucket-sampling)

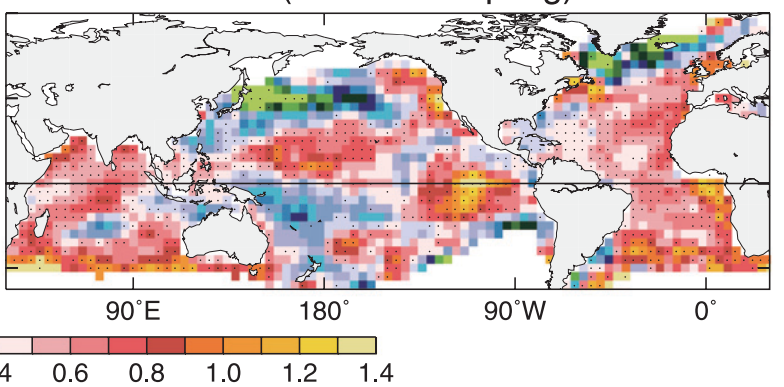

\section{$f$ MOHMAT}

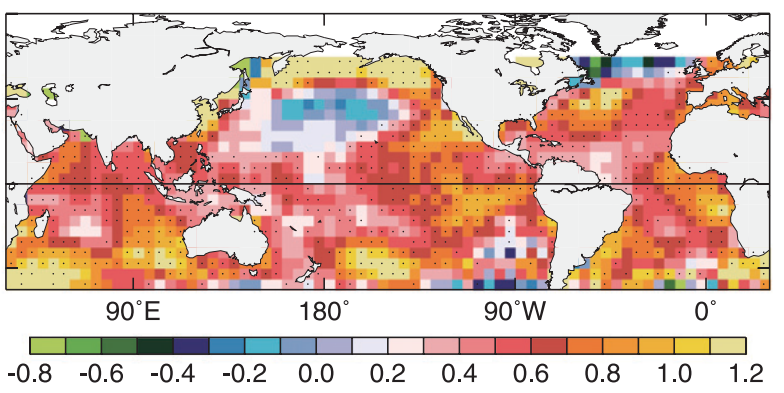

FIG. 16. The 59-yr changes in SST [ ${ }^{\circ} \mathrm{C}(59 \mathrm{yr})^{-1}$ ] obtained from (a) ERSST v3b, (b) HadISST1, (c) ICOADS SST including all measuring methods, and (d) the bucket-sampled SST, and NMAT from (e) ICOADS and (f) MOHMAT. Significant trends exceeding the 90\% confidence level are marked with dots.

To examine dataset dependency of trend estimate, Fig. 16 compares SST trend patterns in HadISST, ERSST, and two versions of the ICOADS SSTs. One version includes all measurements and one only those by bucket sampling. The SST trend patterns from ERSST are generally similar to those in HadISST and ICOADS SST with all measurements, featuring intense warming in the tropical Indian Ocean through the western Pacific, in the central South Pacific, and the tropical Atlantic (Figs. $16 \mathrm{a}-\mathrm{c})$. The cooling trends in the central North Pacific are associated with the strengthening of the Pacific decadal oscillation during the last half-century. Similar cooling trends are found in the North Atlantic south of Greenland associated with the weakening of the Atlantic multidecadal oscillation. The equatorial Pacific trend varies among SST products-a weak equatorial Pacific cooling in HadISST but warming in the ERSST and the
ICOADS SST. Previous studies suggest that the blending of satellite SST in the HadISST is the main source of this equatorial Pacific SST trend sign difference (Deser et al. 2010; Vecchi et al. 2008; Vecchi and Soden 2007). Interestingly, none of these datasets display a SST trend pattern with a weakened zonal SST gradient. As such, they do not appear to be consistent with surface wind and subsurface ocean temperature changes displayed in Figs. 3 and 4.

On the other hand, while being generally similar to the other three SST datasets outside of the tropical IndoPacific, the bucket-sampled SSTs exhibit some significant differences in the western tropical Pacific and the southeastern tropical Indian Ocean (Fig. 16d). The bucketsampled SST trends display less warming in the western than eastern tropical Pacific and less warming in the southeastern than western to central tropical Indian 
Ocean. This acts to reduce the zonal temperature gradient of the tropical Indian and Pacific Oceans and is therefore more consistent with the weakened Walker circulation over the tropical Indo-Pacific. Both NMAT reconstructions from ICOADS and MOHMAT exhibit generally consistent trend patterns with those in the bucket-sampled SSTs, showing enhanced warming over the eastern tropical Pacific and western to central tropical Indian Ocean and reduced warming over the Maritime Continent (Figs. 16e,f). To the extent that marine air temperature follows SST by surface heat exchange, the agreement in warming pattern between NMAT and bucket-sampled SST provides support for the reduced zonal thermal contrast across the tropical Indo-Pacific Oceans. XBT measurements of mixed layer temperature (Figs. 4 and 12) also support a reduced SST gradient over the equatorial Indo-Pacific.

\section{Summary}

We have investigated regional patterns of tropical IndoPacific climate change over the last six decades (1950 to approximately 2009) by synthesizing independent in situ observations and ocean models. Our bias-corrected surface wind data display a significant surface divergence trend over the Maritime Continent and convergence trends over the central equatorial Pacific, which are physically consistent with the patterns of SLP change. The surface wind changes dominate those of surface moisture-flux convergence and explain patterns of marine cloudiness and precipitation changes. The rain gauge and ship observations reveal a significant decrease in land precipitation and marine cloudiness over the Maritime Continent, respectively, with a common seasonality peaking during boreal summer to fall. The changes in precipitation and surface wind from in situ observations are opposite to those from atmospheric reanalyses, calling for caution in the use of reanalysis products for tropical climate change studies. All these findings confirm the notion of a weakened Walker circulation, as highlighted by both observational and modeling studies (Deser et al. 2010; Knutson and Manabe 1995; Vecchi and Soden 2007; Vecchi et al. 2006).

Bias-corrected XBT observations corroborate the atmospheric changes over the tropical Indo-Pacific described in the present study. For instance, consistent with the weaker easterly winds of the Pacific Ocean branch of the Walker circulation a significant cooling is seen in the western equatorial Pacific Ocean at thermocline depth level, while the eastern equatorial Pacific Ocean displays a warming at thermocline depth level. In addition, the eastern and western equatorial Indian Ocean respectively display significant cooling and warming at the thermocline depth level, consistent with the easterly surface wind trend of the weaker Indian Ocean branch of the Walker circulation. Interestingly, both the Pacific and Indian subsurface trends indicate less surface warming around the Maritime Continent than in the eastern equatorial Pacific and western equatorial Indian Ocean and are therefore representative a reduced zonal gradient of surface temperature. The ocean GCM forced by our bias-corrected WASWind actually reproduces a similar reduction in equatorial zonal gradient of ocean temperature and sea level, illustrating the importance of surface wind forcing with realistic long-term trends for oceanic response.

How the observed equatorial Indo-Pacific zonal SST gradient has changed over the past decades is still an unresolved question. Here, we compared the trends in the three widely used SST products (ERSST v3b, HadISST1, and ICOADS SST with all types of measurements), the bucket-sampled SST (ICOADS), and NMAT (ICOADS and MOHMAT4.3). Whereas the former three SST products exhibit no significant change in zonal SST gradient in the tropical Indo-Pacific, both the bucketsampled SST and NMAT show a significant reduction in the zonal temperature gradient. The similar warming patterns between the bucket-sampled SST and NMAT are more consistent with XBT observations of mixed layer temperature change and the weakening of Walker circulation, suggesting that the widely-used SST reconstructions have inherent biases that affect the detection of realistic trend patterns in the tropical Indo-Pacific.

The relative importance of zonal SST gradient changes and the increased atmospheric static stability due to global warming on the Walker circulation changes is currently unresolved (Gastineau et al. 2009; Knutson and Manabe 1995; Ma et al. 2012). The 60-yr trend patterns in the present study are broadly similar to those from historical observations during 1900-2008 (Deser et al. 2010) and multimodel climate projections of CMIP3 models (Vecchi and Soden 2007). This similarity implies that the observed weakening of Walker circulation over the last six decades presented here likely includes the effect of atmospheric composition changes. We note, however, that the magnitude of observed trends is approximately one order of magnitude larger than those displayed in the CMIP3 models (Figs. 14c,d). Power and Kociuba (2011) suggest that contributions from both internal climate variability and global warming are essential to explain the observed Walker circulation weakening seen during the twentieth century. On the other hand, Merrifield (2011) reports a recent shift in tropical western Pacific sea level trends in response to intensified trade winds after the 1990s, implying a strong interdecadal variability over the tropical Pacific. Although it is unclear whether the tropical SST and NMAT trends are 
related to interdecadal variability (Deser and Phillips 2006; Deser et al. 2004), external forcing or a combination of both, our findings of physical consistency among independent ocean-atmospheric observations suggest that ocean-atmosphere coupling plays an important role in the observed weakening of Walker circulation. Such ocean-atmosphere coupling probably shortens the detection time scale for the Walker circulation weakening ( $\sim 60$ yr), while Vecchi et al. (2006) suggest longer detection time scale $(\sim 100 \mathrm{yr})$ for the GHG-induced Walker circulation weakening based on model simulations. Separating global warming effects from natural variability is still a challenge due to the limited instrumental records, large uncertainties, and biases in both observations and models. At this moment in time, comprehensive analysis with long, consistent climate datasets is essential for better understanding of the past climate change and constraining climate models used for future predictions.

Ocean and atmospheric reanalysis products are widely used as "observations" and have provided us with insights into climate variabilities ranging from intraseasonal to decadal time scales. This may not be the case for long-term trends as these products can include spurious trends due to changes in the frequency and spatial resolution of the data used to constrain the reanalysis products (e.g., include reference here). While we have focused on the Walker circulation in the present study, the Hadley circulation change may also be affected by biases in radiosonde observations assimilated into the atmospheric reanalyses (Mitas and Clement 2006). Furthermore, the historical SST products, which are used as the lower boundary condition for long-term integrations of atmospheric models, seem to have large uncertainties especially in the equatorial Indo-Pacific. Therefore, sustained efforts are needed for the development and improvement of homogeneous data reconstructions for an improved determination and understanding of both regional and global climate change. The present study has described the observational evidence for the weakened Walker circulation over the last six decades, but its physical mechanisms need further investigation.

Acknowledgments. We thank Clara Deser for useful discussions, Jun Matsumoto, and JMA for providing the ASEAN monthly climate data archive. The original ship reports for this work are from RDA maintained by CISL at NCAR, available at http://dss.ucar.edu as dataset number ds540.0. The WASWind product is available at http://iprc.soest.hawaii.edu/ tokinaga/waswind. This work is supported by NSF, NASA, NOAA, and JAMSTEC.

\section{REFERENCES}

Abram, N. J., M. K. Gagan, J. E. Cole, W. S. Hantoro, and M. Mudelsee, 2008: Recent intensification of tropical climate variability in the Indian Ocean. Nat. Geosci., 1, 849-853.

Alexander, M. A., I. Blade, M. Newman, J. R. Lanzante, N. C. Lau, and J. D. Scott, 2002: The atmospheric bridge: The influence of ENSO teleconnections on air-sea interaction over the global oceans. J. Climate, 15, 2205-2231.

Annamalai, H., J. Potemra, R. Murtugudde, and J. P. McCreary, 2005: Effect of preconditioning on the extreme climate events in the tropical Indian Ocean. J. Climate, 18, 3450-3469.

Ashok, K., W. L. Chan, T. Motoi, and T. Yamagata, 2004: Decadal variability of the Indian Ocean dipole. Geophys. Res. Lett., 31, L24207, doi:10.1029/2004GL021345.

Balmaseda, M. A., A. Vidard, and D. L. T. Anderson, 2008: The ECMWF ocean analysis system: ORA-S3. Mon. Wea. Rev., 136, 3018-3034.

Bunge, L., and A. J. Clarke, 2009: A verified estimation of the El Niño index Niño-3.4 since 1877. J. Climate, 22, 39793992.

Bunker, A. F., 1980: Trends of variables and energy fluxes over the Atlantic Ocean from 1948 to 1972. Mon. Wea. Rev., 108, 720732.

Cai, W., T. Cowan, and A. Sullivan, 2009a: Recent unprecedented skewness towards positive Indian Ocean Dipole occurrences and its impact on Australian rainfall. Geophys. Res. Lett., 36, L11705, doi:10.1029/2009g1037604.

_ A. Sullivan, and T. Cowan, 2009b: Climate change contributes to more frequent consecutive positive Indian Ocean Dipole events. Geophys. Res. Lett., 36, L23704, doi:10.1029/ $2009 \mathrm{gl} 1040163$.

Cane, M. A., and Coauthors, 1997: Twentieth-century sea surface temperature trends. Science, 275, 957-960.

Cardone, V. J., J. G. Greenwood, and M. A. Cane, 1990: On trends in historical marine wind data. J. Climate, 3, 113-127.

Carton, J. A., G. Chepurin, X. H. Cao, and B. Giese, 2000: A simple ocean data assimilation analysis of the global upper ocean 1950-95. Part I: Methodology. J. Phys. Oceanogr., 30, 294-309.

Chang, C. P., Z. Wang, J. McBride, and C. H. Liu, 2005: Annual cycle of Southeast Asia-Maritime continent rainfall and the asymmetric monsoon transition. J. Climate, 18, 287-301.

Chen, J. Y., A. D. Del Genio, B. E. Carlson, and M. G. Bosilovich, 2008: The spatiotemporal structure of twentieth-century climate variations in observations and reanalyses. Part I: Longterm trend. J. Climate, 21, 2611-2633.

Christensen, J. H., and Coauthors, 2007: Regional climate projections. Climate Change 2007: The Physical Science Basis, S. Solomon et al., Eds., Cambridge University Press, 847940.

Collins, M., and Coauthors, 2010: The impact of global warming on the tropical Pacific Ocean and El Niño. Nat. Geosci., 3, 391397.

Deser, C., and A. S. Phillips, 2006: Simulation of the 1976/77 climate transition over the North Pacific: Sensitivity to tropical forcing. J. Climate, 19, 6170-6180.

,-- , and J. W. Hurrell, 2004: Pacific interdecadal climate variability: Linkages between the tropics and the North Pacific during boreal winter since 1900. J. Climate, 17, 3109-3124.

$\ldots$, A. Phillips, and M. A. Alexander, 2010: Twentieth century tropical sea surface temperature trends revisited. Geophys. Res. Lett., 37, L10701, doi:10.1029/2010GL043321. 
DiNezio, P. N., A. C. Clement, G. A. Vecchi, B. J. Soden, and B. P. Kirtman, 2009: Climate response of the equatorial Pacific to global warming. J. Climate, 22, 4873-4892.

Du, Y., and S.-P. Xie, 2008: Role of atmospheric adjustments in the tropical Indian Ocean warming during the 20th century in climate models. Geophys. Res. Lett., 35, L08712, doi:10.1029/ 2008 GL033631.

Emori, S., and S. J. Brown, 2005: Dynamic and thermodynamic changes in mean and extreme precipitation under changed climate. Geophys. Res. Lett., 32, L17706, doi:10.1029/ 2005 GL023272.

Gastineau, G., L. Li, and H. Le Treut, 2009: The Hadley and Walker circulation changes in global warming conditions described by idealized atmospheric simulations. J. Climate, 22 , 3993-4013.

Hagemann, S., K. Arpe, and L. Bengtsson, 2005: Validation of the hydrological cycle of ERA-40. ERA-40 Project Rep. Series 24, $42 \mathrm{pp}$.

Han, W. Q., G. A. Meehl, and A. X. Hu, 2006: Interpretation of tropical thermocline cooling in the Indian and Pacific oceans during recent decades. Geophys. Res. Lett., 33, L23615, doi:10.1029/2006GL027982.

_ - and Coauthors, 2010: Patterns of Indian Ocean sea-level change in a warming climate. Nat. Geosci., 3, 509-584.

Hansen, J., and Coauthors, 2005: Earth's energy imbalance: Confirmation and implications. Science, 308, 1431-1435.

_- M. Sato, R. Ruedy, K. Lo, D. W. Lea, and M. Medina-Elizade, 2006: Global temperature change. Proc. Natl. Acad. Sci. USA, 103, 14 288-14 293.

Held, I. M., and B. J. Soden, 2006: Robust responses of the hydrological cycle to global warming. J. Climate, 19, 5686-5699.

Kalnay, E., and Coauthors, 1996: The NCEP/NCAR 40-Year Reanalysis Project. Bull. Amer. Meteor. Soc., 77, 437-471.

Karnauskas, K. B., R. Seager, A. Kaplan, Y. Kushnir, and M. A. Cane, 2009: Observed strengthening of the zonal sea surface temperature gradient across the equatorial Pacific Ocean. J. Climate, 22, 4316-4321.

Kendall, M. G., 1975: Rank Correlation Methods. Griffin, 202 pp.

Kent, E. C., and P. K. Taylor, 2006: Toward estimating climatic trends in SST. Part I: Methods of measurement. J. Atmos. Oceanic Technol., 23, 464-475.

Knutson, T. R., and S. Manabe, 1995: Time-mean response over the tropical Pacific to increased $\mathrm{CO}_{2}$ in a coupled oceanatmosphere model. J. Climate, 8, 2181-2199.

Ma, J., S.-P. Xie, and Y. Kosaka, 2012: Mechanisms for tropical tropospheric circulation change in response to global warming. J. Climate, in press.

McGregor, S., N. J. Holbrook, and S. B. Power, 2007: Interdecadal sea surface temperature variability in the equatorial Pacific Ocean. Part I: The role of off-equatorial wind stresses and oceanic Rossby waves. J. Climate, 20, 2643-2658.

Meng, Q., M. Latif, W. Park, N. S. Keenlyside, V. A. Semenov, and T. Martin, 2012: Twentieth century Walker Circulation change: Data analysis and model experiments. Climate Dyn., doi:10.1007/s00382-011-1047-8, in press.

Merrifield, M. A., 2011: A shift in western tropical Pacific sea level trends during the 1990s. J. Climate, 24, 4126-4138.

Mitas, C. M., and A. Clement, 2006: Recent behavior of the Hadley cell and tropical thermodynamics in climate models and reanalyses. Geophys. Res. Lett., 33, L01810, doi:10.1029/ $2005 \mathrm{gl} 024406$.

Norris, J. R., 1999: On trends and possible artifacts in global ocean cloud cover between 1952 and 1995. J. Climate, 12, 1864-1870.
- 2005: Trends in upper-level cloud cover and surface divergence over the tropical Indo-Pacific Ocean between 1952 and 1997. J. Geophys. Res., 110, D21110, doi:10.1029/ $2005 \mathrm{jd} 006183$

Ogata, T., 2009: Interannual modulation of intraseasonal upperocean variability in the Indo-Pacific warm water region. Ph.D. dissertation, University of Tokyo, $127 \mathrm{pp}$.

Onogi, K., and Coauthors, 2007: The JRA-25 Reanalysis. J. Meteor. Soc. Japan, 85, 369-432.

Pacanowski, R. C., and S. M. Griffies, 2000: MOM 3.0 manual. Geophysical Fluid Dynamics Laboratory/National Oceanic and Atmospheric Administration, $680 \mathrm{pp}$.

Power, S. B., and I. N. Smith, 2007: Weakening of the Walker Circulation and apparent dominance of El Niño both reach record levels, but has ENSO really changed? Geophys. Res. Lett., 34, L18702, doi:10.1029/2007g1030854.

—, and G. Kociuba, 2011: What caused the observed twentiethcentury weakening of the Walker circulation? J. Climate, 24, 6501-6514.

Ramage, C. R., 1987: Secular changes in reported surface wind speeds over the ocean. J. Climate Appl. Meteor., 26, 525528.

Rayner, N. A., and Coauthors, 2003: Global analyses of sea surface temperature, sea ice, and night marine air temperature since the late nineteenth century. J. Geophys. Res., 108, 4407, doi:10.1029/2002jd002670.

Saji, N. H., B. N. Goswami, P. N. Vinayachandran, and T. Yamagata, 1999: A dipole mode in the tropical Indian Ocean. Nature, 401, 360-363.

Sen, P. K., 1968: Estimates of the regression coefficient based on Kendall's tau. J. Amer. Stat. Assoc., 63, 1379-1389.

Smith, T. M., and R. W. Reynolds, 2004: Improved extended reconstruction of SST (1854-1997). J. Climate, 17, 24662477.

, T. C. Peterson, and J. Lawrimore, 2008: Improvements to NOAA's historical merged land-ocean surface temperature analysis (1880-2006). J. Climate, 21, 2283-2296.

Sohn, B. J., and S. C. Park, 2010: Strengthened tropical circulations in past three decades inferred from water vapor transport. J. Geophys. Res., 115, D15112, doi:10.1029/ 2009jd013713.

Thomas, B. R., E. C. Kent, V. R. Swail, and D. I. Berry, 2008: Trends in ship wind speeds adjusted for observation method and height. Int. J. Climatol., 28, 747-763.

Timmermann, A., S. McGregor, and F.-F. Jin, 2010: Wind effects on past and future regional sea level trends in the southern Indo-Pacific. J. Climate, 23, 4429-4437.

Tokinaga, H., and S.-P. Xie, 2011a: Wave- and Anemometer-based Sea Surface Wind (WASWind) for climate change analysis. J. Climate, 24, 267-285.

$\longrightarrow$, and $-2011 \mathrm{~b}$ : Weakening of the equatorial Atlantic cold tongue over the past six decades. Nat. Geosci., 4, 222226.

Trenary, L. L., and W. Han, 2008: Causes of decadal subsurface cooling in the tropical Indian Ocean during 1961-2000. Geophys. Res. Lett., 35, L17602, doi:10.1029/2008GL034687.

Trenberth, K. E., D. P. Stepaniak, J. W. Hurrell, and M. Fiorino, 2001: Quality of reanalyses in the tropics. J. Climate, 14, 14991510.

Uppala, S. M., and Coauthors, 2005: The ERA-40 Re-Analysis. Quart. J. Roy. Meteor. Soc., 131, 2961-3012.

Vecchi, G. A., and B. J. Soden, 2007: Global warming and the weakening of the tropical circulation. J. Climate, 20, 4316-4340. 
- — - A. T. Wittenberg, I. M. Held, A. Leetmaa, and M. J. Harrison, 2006: Weakening of tropical Pacific atmospheric circulation due to anthropogenic forcing. Nature, 441, 73-76.

A. Clement, and B. J. Soden, 2008: Examining the tropical Pacific's response to global warming. Eos, Trans. Amer. Geophys. Union, 89, 9, doi:10.1029/2008EO090002.

Ward, M. N., and B. J. Hoskins, 1996: Near-surface wind over the Global Ocean 1949-1988. J. Climate, 9, 1877-1895.

Whysall, K. D. B., N. S. Cooper, and G. R. Bigg, 1987: Long-term changes in the tropical Pacific surface wind field. Nature, 327, 216-219.

Wijffels, S. E., and Coauthors, 2008: Changing expendable bathythermograph fall rates and their impact on estimates of thermosteric sea level rise. J. Climate, 21, 5657-5672.

Williams, B., and A. G. Grottoli, 2010: Recent shoaling of the nutricline and thermocline in the western tropical Pacific. Geophys. Res. Lett., 37, L22601, doi:10.1029/2010GL044867.

Willmott, C. J., and S. M. Robeson, 1995: Climatologically aided interpolation (CAI) of terrestrial air temperature. Int. J. Climatol., 15, 221-229.
Woodruff, S. D., and Coauthors, 2010: ICOADS Release 2.5: Extensions and enhancements to the surface marine meteorological archive. Int. J. Climatol., 31, 951-967, doi:10.1002/joc.2103.

$\mathrm{Wu}, \mathrm{R}$. , and S.-P. Xie, 2003: On equatorial Pacific surface wind changes around 1977: NCEP-NCAR reanalysis versus COADS observations. J. Climate, 16, 167-173.

Xie, S.-P., H. Annamalai, F. A. Schott, and J. P. McCreary, 2002: Structure and mechanisms of South Indian Ocean climate variability. J. Climate, 15, 864-878.

— C. Deser, G. A. Vecchi, J. Ma, H. Teng, and A. T. Wittenberg, 2010: Global warming pattern formation: Sea surface temperature and rainfall. J. Climate, 23, 966-986.

Yang, H. J., and F. Y. Wang, 2009: Revisiting the thermocline depth in the equatorial Pacific. J. Climate, 22, 3856-3863.

Yu, B., and F. W. Zwiers, 2010: Changes in equatorial atmospheric zonal circulations in recent decades. Geophys. Res. Lett., 37, L05701, doi:10.1029/2009g1042071.

Zheng, X. T., S.-P. Xie, G. A. Vecchi, Q. Y. Liu, and J. Hafner, 2010: Indian Ocean dipole response to global warming: Analysis of ocean-atmospheric feedbacks in a coupled model. J. Climate, 23, 1240-1253. 